\title{
Human trafficking for labour exploitation: the results of a two-phase systematic review mapping the European evidence base and synthesising key scientific research evidence
}

\author{
Ella Cockbain $^{1}$ (D) Kate Bowers $^{1}$ (D) Galina Dimitrova $^{1}$
}

Published online: 6 April 2018

(C) The Author(s) 2018

\begin{abstract}
Objectives Our objectives were (1) to systematically map the contours of the European evidence base on labour trafficking, identifying its key characteristics, coverage, gaps, strengths and weaknesses and (2) to synthesise key scientific research.

Methods We took a two-phase approach: a systematic map followed by a detailed synthesis of key scientific research evidence. Our search strategy included 15 databases, hand searches of additional journals, backwards searches, snowball searches and expert recommendations. We identified and screened 6106 records, mapped 152 and synthesised eight.

Results Overall, the literature was limited and fragmented. Reports produced by official agencies dominated; academic authorship and peer-reviewed outputs were comparatively rare. Few publications met minimum scientific standards. Qualitative designs outweighed quantitative ones. Publications typically described trafficking's problem profile and/or discussed interventions; they rarely assessed trafficking's impacts or evaluated interventions. Even among the key scientific research, the quality of evidence was variable and often low. Particular weaknesses included poor methods reporting, unclear or imprecise results and conclusions not properly grounded in the data. The synthesised studies were all exploratory, also sharing other design features. Common themes identified included: poor treatment of victims; diversity of sectors affected and commonalities among victims; inadequacies of current responses; and barriers to interventions.
\end{abstract}

Electronic supplementary material The online version of this article (https://doi.org/10.1007/s11292-0179321-3) contains supplementary material, which is available to authorized users.

Ella Cockbain

e.cockbain@ucl.ac.uk

1 Department of Security and Crime Science, University College London (UCL), 35 Tavistock

Square, London WC1H 9EZ, UK 
Conclusions There is a lack of high-quality studies into European labour trafficking. Methodological opacity, insufficient rigour and publication in non-indexed locations impede the identification, assessment and synthesis of evidence. Adherence to higher reporting standards would further the field's development and particular research gaps should be addressed.

Keywords Exploitation · Forced labour · Human trafficking · Immigration · Migration · Organised crime $\cdot$ Modern slavery $\cdot$ Servitude $\cdot$ Systematic review $\cdot$ Systematic map

\section{Introduction and background}

Human trafficking, sometimes known as modern slavery ${ }^{1}$, is often framed as one of the greatest organised crime threats facing modern society. Numerous reports and, to a lesser extent, research studies have argued that human trafficking adversely affects the stability, security and well-being of individual victims, entire communities, industries and even nations (Belser 2005; Home Office 2012; Kelly 2002; Zimmerman et al. 2006). With increases in political, media and public attention since the 1990s has come a host of legislation and policy-making designed to tackle trafficking (Goodey 2008; Van Der Laan et al. 2011). Yet, the demand for robust research to inform evidence-based policy and practice far outpaces its supply. Debate and decision-making often rely instead on anecdotal evidence, supposition, rhetoric or popular wisdom.

Systematic reviews of any aspect of the trafficking literature are rare; notable exceptions have focused on trafficking's health impacts (Oram et al. 2012a; Ottisova et al. 2016), interventions around sex trafficking (Macy and Graham 2012; Van Der Laan et al. 2011) and the state of trafficking research more broadly (Gozdziak and Bump 2008). In contrast, non-systematic reviews of the trafficking literature and commentaries are fairly common but have greater potential for bias in the identification, selection, assessment and interpretation of evidence (Gough et al. 2012). These literature reviews' key findings proved helpful in informing our systematic review's design and providing context.

Among the most common criticisms of the trafficking literature are the limited focus and coverage (e.g. thematic and geographical skews), the predominance of purely descriptive work, methodological opacity, weak research design (e.g. questionable assumptions, inappropriate datasets), sampling biases (a common shortcoming when working with hidden populations), ill-founded inferences, a tendency to be emotionally and/or politically charged and lack balance, and poor-quality statistics (e.g. projections, estimates with huge ranges, lack of rigour in their generation and interpretation) (Andrees and van der Linden 2005; Aronowitz 2001, 2009; Di Nicola 2007; Feingold 2010; Goodey 2008; Kelly 2005; Laczko and Gozdziak 2005; Lehti and Aromaa 2006; Tyldum and Brunovskis 2005).

The overwhelming focus on sex trafficking has left other trafficking types overlooked (Andrees and Linden 2005; Home Office 2007; Kelly 2005; Laczko and

\footnotetext{
${ }^{1}$ Although these terms are often used interchangeably, we deliberately stick to 'human trafficking' throughout this article. There is an internationally agreed and widely used definition of human trafficking but not for modern slavery.
} 
Gozdziak 2005; Surtees 2008). Major knowledge gaps persist around even basic aspects of labour trafficking, for example, let alone the effectiveness of countermeasures (Andrees and Linden 2005; Home Office 2007; Kelly 2005; Laczko and Gozdziak 2005). A non-systematic review of the United Kingdom's (UK) literature on labour trafficking identified just nine studies, none of which included quantitative analysis (Home Office 2007).

Yet, labour trafficking is increasingly prioritised at national and international levels (European Commission 2012; Home Office 2011a, 2011b, 2014; U.S. Department of State 2014). In the UK, for example, 2014's overall rise in trafficking referrals included a particularly steep growth in suspected labour trafficking cases (National Crime Agency 2015). Analysing the characteristics of the 2727 trafficking victims ${ }^{2}$ identified in the UK from 2009 to 2014, Cockbain and Bowers (2015) found that the most common exploitation type overall was labour (44\%), ahead of both sex $(41 \%)$ and domestic servitude (12\%). Several other European Union member states have reported that labour trafficking is on the rise (European Commission 2016). Countries and regions appear to vary greatly, however, both in the volume of identified labour trafficking cases and what proportion of the local trafficking problem they represent (Belser et al. 2005; de Jonge 2005; United Nations Office on Drugs and Crime 2012, 2014).

We identified a clear need for a systematic review of the evidence on labour trafficking. We decided to focus on Europe for several reasons. First, we were aware of a particular demand for such a product here as labour trafficking had been singled out as a priority in the European Union's counter-trafficking strategy (European Commission 2012) and in EUROPOL's operational action plan on trafficking (Government of the Netherlands 2016). Second, trafficking has pronounced regional variation and, given the European interest, it made sense to focus on European evidence. Third, a narrower geographical remit was a useful, pragmatic counterbalance to our review's otherwise broad thematic scope and the diverse array of evidence we intended to consider.

Our overarching review objectives were to assess the shape of the overall evidence base on European labour trafficking, identifying coverage and gaps, strengths and weaknesses and to synthesise key scientific research evidence on the problem and associated counter-measures. We favoured an exploratory two-phase approach (a systematic map followed by a targeted synthesis), as recommended for reviews like ours that deal with broad topics and poorly-charted domains (EPPI-Centre 2010; Gough and Thomas 2012; Oliver and Sutcliffe 2012). The particular contributions of the mapping stage are outlining the contours of the literature and informing the direction and interpretation of the synthesis (Gough 2007; Gough and Thomas 2012; Oliver and Sutcliffe 2012).

Our review questions were:

1. What is the overall state of the empirical evidence base on the scale, nature and impacts of labour trafficking affecting Europe and on-the-ground counter-measures? (Systematic map)

\footnotetext{
$\overline{2}$ Based on all referrals to the UK's 'National Referral Mechanism' from 1 April 2009 to 30 September 2014. Victims are defined as individuals granted positive 'conclusive grounds' decisions.
} 
2. What can we learn from key scientific research evidence about the scale, nature and impacts of labour trafficking affecting Europe and on-the-ground counter-measures? (Synthesis)

We defined 'human trafficking' in accordance with international law as:

the recruitment, transportation, transfer, harbouring or receipt of persons, by means of the threat or use of force or other forms of coercion, of abduction, of fraud, of deception, of the abuse of power or of a position of vulnerability or of the giving or receiving of payments or benefits to achieve the consent of a person having control over another person, for the purpose of exploitation. Exploitation shall include, at a minimum, the exploitation of the prostitution of others or other forms of sexual exploitation, forced labour or services, slavery or practices similar to slavery, servitude or the removal of organs. (United Nations 2000, p. 42)

There is no equivalent agreed and specific definition of 'labour trafficking'. Even within the European Union, there is variation between and within states in what is seen to constitute trafficking for labour exploitation. Particular discrepancies exist around whether the term covers exploitation in criminal industries (e.g. pickpocketing, cannabis cultivation) and/or within the household (domestic servitude). Our review definition of labour trafficking was that implicitly used in the UK for data collection and case monitoring (via the 'National Referral Mechanism'): exploitation of any bodily labour except sexual services and domestic servitude. This definition covers labour in both legal and illegal industries but excludes domestic servitude. Analysis of UK trafficking data has revealed statistically significant differences between victims of domestic servitude and labour trafficking (Cockbain and Bowers 2015). Such results suggest that treating domestic servitude as part of labour trafficking risks conflating two potentially divergent issues and obscuring key differences. It is also worth noting that, although there is conceptual overlap between 'labour trafficking' and 'forced or compulsory labour' (as defined in international $\mathrm{law}^{3}$ ), the two issues are not equivalent and each can occur without the other.

We defined 'Europe' as all European Union (EU) member states, candidates and potential candidates plus additional countries not affiliated with the EU but located within the geographical territory commonly understood as Europe (e.g. Switzerland, Norway, Russia). The full list of countries covered is:

Albania, Andorra, Austria, Belarus, Belgium, Bosnia and Herzegovina, Bulgaria, Croatia, Cyprus, Czech Republic, Denmark, Estonia, Finland, France, Germany, Greece, Holy See, Hungary, Iceland, Ireland, Italy, Kosovo, Latvia, Liechtenstein, Lithuania, Luxembourg, Macedonia (The Former Yugoslav Republic of), Malta, Moldova, Monaco, Montenegro, Netherlands, Norway, Poland, Portugal, Romania, Russian Federation, San Marino, Serbia, Slovakia, Slovenia, Spain, Sweden, Switzerland, Turkey, Ukraine and the UK.

\footnotetext{
${ }^{3}$ According to the International Labour Organisation Convention on Forced Labour, 'forced or compulsory labour shall mean all work or service which is exacted from any person under the menace of any penalty and for which the said person has not offered himself voluntarily' (International Labour Organization 1930). Specific exceptions apply, covering military service for example.
} 


\section{Methods}

\section{Ethics, review registration and protocol}

Ethical approval was not required for this project. We registered our review prospectively in the PROSPERO International Prospective Register of Systematic Reviews (Cockbain et al. 2014), although our eventual review was far more comprehensive than what we had initially planned and registered. Our protocol adhered to the Preferred Reporting Items for Systematic Review and Meta-analysis Protocols (PRISMA-P) guidelines (see Appendix 1 for the checklist). There is no equivalent PRISMA tool for systematic mapping.

\section{Stakeholder engagement}

We engaged with key stakeholders (over 100 in total) to ensure external scrutiny, draw on their diverse perspectives and experiences and maximise the review's relevance and practical application (Rees and Oliver 2012). Table 1 contains details about the stakeholder groups and their composition. We initially consulted with the EMPACT

Table 1 Stakeholder engagement

\begin{tabular}{|c|c|c|c|}
\hline $\begin{array}{l}\text { Group of } \\
\text { stakeholders }\end{array}$ & Description of group & $\begin{array}{l}\text { Number of } \\
\text { members } \\
\text { consulted }\end{array}$ & Countries represented \\
\hline $\begin{array}{l}\text { EMPACT } \\
\text { Initiative }\end{array}$ & $\begin{array}{l}\text { Formal group of counter-trafficking } \\
\text { leads tasked with coordinating and } \\
\text { improving European responses to hu- } \\
\text { man trafficking. Vast majority of } \\
\text { members from national law enforce- } \\
\text { ment but group also includes repre- } \\
\text { sentatives of transnational organisa- } \\
\text { tions like EUROPOL, CEPOL and } \\
\text { EUROJUST. }\end{array}$ & 71 & $\begin{array}{l}\text { Belgium, Bulgaria, Cyprus, } \\
\text { Czech Republic, Denmark, France, } \\
\text { Ireland, Hungary, Latvia, } \\
\text { Luxembourg, Malta, Netherlands, } \\
\text { Poland, Portugal, Romania, Slovak } \\
\text { Republic, Slovenia, Spain, Sweden, } \\
\text { Switzerland, UK. }\end{array}$ \\
\hline $\begin{array}{l}\text { UK Threat } \\
\text { Group on } \\
\text { Human } \\
\text { Trafficking }\end{array}$ & $\begin{array}{l}\text { Formal multi-agency group that leads } \\
\text { the UK's strategic response to human } \\
\text { trafficking. Members include key rep- } \\
\text { resentatives from the Home Office, } \\
\text { Foreign Office, Gangmasters' Licenc- } \\
\text { ing Authority, tax authorities, police, } \\
\text { National Crime Agency, Crown Pros- } \\
\text { ecution Service and the Child Traf- } \\
\text { ficking Advice Centre. }\end{array}$ & 30 & UK. \\
\hline $\begin{array}{l}\text { Additional } \\
\text { experts }\end{array}$ & $\begin{array}{l}\text { Not a formal group but rather a set of } \\
\text { academics and other researchers with } \\
\text { clear expertise on labour trafficking. } \\
\text { Identified on an ad hoc basis through } \\
\text { their publications and/or discussions at } \\
\text { various trafficking related conferences } \\
\text { and events. }\end{array}$ & 6 & Austria, Finland, Netherlands, UK. \\
\hline
\end{tabular}


group and the UK Threat Group on our review aims and design. Later, both these two groups and the additional experts had the opportunity to review our preliminary findings and plans for targeted synthesis, provide feedback and identify any outstanding publications for consideration.

\section{Search strategy}

We used varied and complementary search strategies, designed to retrieve relevant publications from both the academic and grey literatures. First, we ran keyword searches of the following fifteen databases:

1. ASSIA (Applied Social Sciences Index and Abstracts)

2. Continental Europe Database

3. Criminal Justice Database

4. East Europe, Central Europe Database

5. ERIC (Education Resources Information Center)

6. IBSS (International Bibliography of the Social Sciences)

7. NCJRS (National Criminal Justice Reference System) Abstracts Database

8. Proquest theses and dissertations

9. PsycINFO

10. PsycEXTRA

11. SCOPUS

12. Social Policy and Practice

13. Social Science Database

14. Sociological Abstracts

15. Web of Science.

Second, we conducted manual searches of six journals, a selection chosen because we knew them to contain trafficking research but they were not (fully) indexed in the above databases. They were: Brown Journal of World Affairs; Criminology and Public Policy; Policing: A Journal of Policy and Practice; Health and Human Rights; International Health; and Journal of Immigrant and Minority Health. Third, we ran backwards searches on the contents of two major bibliographies we found that catalogued publications on human trafficking (Farquet et al. 2005; Gozdziak et al. 2015). Fourth, we conducted backwards searches on any trafficking-related reviews we encountered and snowball searches of the other publications we mapped. Finally, we asked stakeholders if they knew of any further relevant publications we had missed.

The range of issues that labour trafficking encompasses and the lack of definitional consistency and clarity meant we needed broad and varied search terms. Our search terms (Appendix 2) were designed to capture synonyms, variants and closely associated issues around both of the two fundamental constructs involved in labour trafficking, namely human trafficking and labour exploitation. We were aware that publications might deal, for example, with 'trafficking in agriculture' without specifically (and arguably redundantly) labelling this phenomenon 'labour trafficking'. As a safeguard, we designed our search terms to also include, as an alternative to the generic category 'labour', some specific industries commonly associated with labour trafficking in the 
academic and grey literature (Andrees and Linden 2005; Home Office 2007, 2012; National Crime Agency 2014), policy discourse and media debate.

\section{Inclusion criteria and study selection}

We uploaded search results to specialist systematic review software (EPPI 4 Reviewer). Most of our results came from database searches and were returned in a format suited to screening on title and abstract; this worked as an initial sift before full text screening. Results from other sources typically lacked abstracts and so we proceeded directly to full text screening. We used the sequence of inclusion criteria detailed in Table 2. The first criterion was built into the searches and the second was applicable to full text screening only, whereas all the rest were used for both title and abstract and full text screening.

Table 2 Inclusion criteria for the systematic map

\begin{tabular}{|c|c|c|}
\hline $\begin{array}{l}\text { Inclusion } \\
\text { criterion }\end{array}$ & Summary & Further details/explanation \\
\hline
\end{tabular}

$\begin{array}{ll}\begin{array}{l}\text { 1. Publication } \\ \text { date }\end{array} & \text { Publication between 1 January } \\ & 2000 \text { and 13 July } 2015\end{array}$

date 2000 and 13 July 2015

\section{Accessibility Full text accessible}

\section{Broad} relevance

Addresses modern day human trafficking and uses data generated from 1990 onwards

\begin{abstract}
End date is when our searches began. Start date is a key year for trafficking: international and legally-binding consensus on what constitutes trafficking was finally reached in 2000 (United Nations 2000). Until then, definitions were so notoriously divergent (Aronowitz 2001) that including earlier publications could have undermined the comparability of the studies reviewed.

We conducted extensive searches via the British Library, our institutional library/e-library, commercial booksellers, specific relevant websites and general search engines. If we could not find a full text in this way, we contacted authors directly requesting a copy. Only if all this did not work did we exclude a text for being inaccessible.
\end{abstract}

We chose 1990 to give a reasonable window for data collection for studies from the start of our publication date range while still retaining a focus on modern day trafficking and filtering out material on earlier forms of unfree labour (e.g. slavery in classical Greece or nineteenth century America) that might feasibly meet the research definition (United Nations 2000) but would not be considered human trafficking in the standard sense.

Our research definition of labour excluded domestic servitude, but there is little consensus about the parameters of what constitutes labour trafficking. To maintain focus but support an inclusive approach to evidence, we excluded publications dealing exclusively with trafficking for domestic servitude but included those that addressed 
Table 2 (continued)

\begin{tabular}{|c|c|c|}
\hline $\begin{array}{l}\text { Inclusion } \\
\text { criterion }\end{array}$ & Summary & Further details/explanation \\
\hline
\end{tabular}

\section{Geography Deals with labour trafficking into, within or from a European country.}

6. Language Is in English

$\begin{array}{ll}\text { 7. Empirical } & \text { Must contain empirical data on European } \\ \text { data } & \text { labour trafficking }\end{array}$

8. No double Is the single most relevant and empirically counting labour trafficking in a way that also covered, implicitly or explicitly, domestic servitude.

One or more countries that we defined as European countries features in the publication as a site for primary data collection or source of secondary data.

For practical reasons we only included English language publications. This language restriction introduces constraints. To have conducted a fully inclusive review on this front, we would have needed the capacity to run searches in (at a minimum) all European languages, screen results and process the contents of those qualifying for inclusion. Considering the number of languages spoken across Europe, this would have been an untenable undertaking.

Under the category 'empirical data' we included evaluations, reviews (systematic or not) and other primary research, as well as empirically-grounded descriptions of administrative and other data. We excluded entirely theoretical pieces, commentaries, training manuals and handbooks, news reports, media content analyses and work concerned with anti-trafficking law or policy in purely normative terms.

If we found multiple publications that used data from the same enquiry, we selected for inclusion the one that we deemed the most relevant and empirically rich. In some cases, we came across multi-country studies that resulted in the publication of single-country studies and multi-country

overviews/comparative analyses. In such instances, we used the multi-country overviews.

Each result was screened by one of two reviewers. We first piloted our screening codebook $^{4}$ by double-screening 50 studies. We identified, discussed and resolved sources of disagreement and refined the codebook as necessary. We later tested for inter-rater reliability by double-coding a randomly selected $5 \%(n=216)$ of the total records screened on title and abstract. The results indicated strong consistency between coders (McHugh 2012): 95\% agreement on inclusion/exclusion and a Cohen's kappa value of 0.8 .

\footnotetext{
${ }^{4}$ A screening codebook is a reference tool that provides information to reviewers about how to apply the screening criteria in practice. Our final codebook contained the information in Table 2 plus relevant supporting documentation (e.g. the list of European countries).
} 


\section{An overview of our review process}

Figure 1 shows the flow of documents through the review. Our searches yielded 6106 records; once we had removed duplicates, 4474 unique publications remained. We mapped 152 of them and synthesised eight.

\section{Phase 1: the systematic map}

We mapped the full texts using a detailed data extraction form (Appendix 3). A single reviewer coded the text for the map. For quality assurance purposes, a second reviewer double-coded a randomly selected $10 \%(n=15)$ of texts. A comparison of the exact codes assigned showed a high degree of consistency between coders $(86 \%)$.

\section{Phase 2: the detailed synthesis}

The systematic map highlighted the methodological weaknesses of the literature, which influenced how we targeted our synthesis. We selected studies for inclusion using the criteria in Table 3. Figure 2 is a graphical depiction of how we assessed publications against the first criterion in Table 3: whether or not they contained 'scientific research'.

Eight publications met the inclusion criteria for synthesis. They varied in their design, methods and foci and included substantial qualitative material. Consequently, we designed our data extraction form (Appendix 4) to be broad and inclusive, simple and to allow for narrative detail. Our intention was to draw out further methodological information and

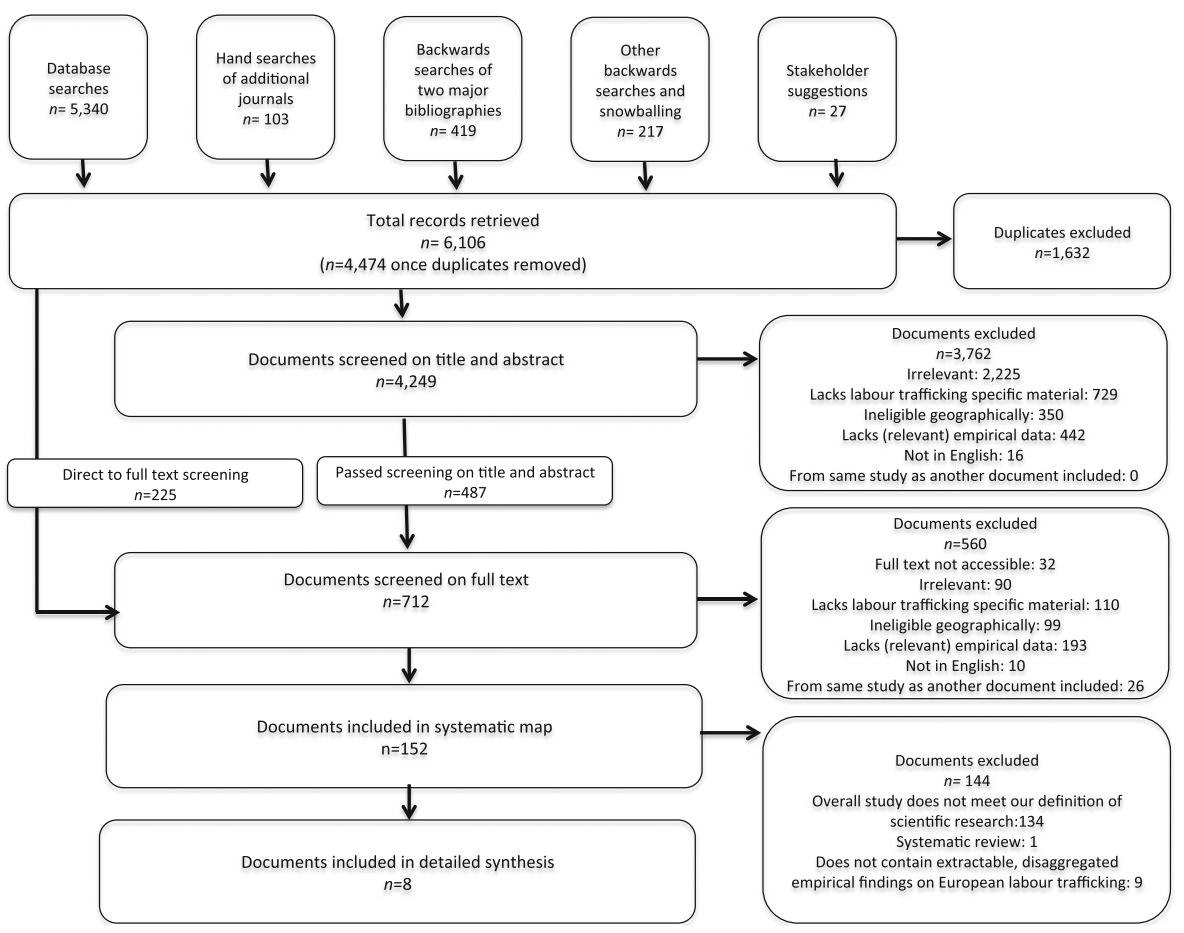

Fig. 1 Flow of documents through our review 
summarise key findings, conclusions and recommendations. Where studies included but were not limited to European labour trafficking, we coded in relation to material on this topic only. Two studies in the sample were book chapters (overviews of multi-country studies) (Jokinen and Ollus 2011; Rijken 2011); in both cases, we used the entire books to get methodological information and complete the quality assessment. One reviewer did the coding in full and a second reviewer revised and commented on their outputs for validation and quality assurance. The few discrepancies that arose relating to what the two reviewers saw as key results and conclusions were easily resolved in discussion.

Table 3 Inclusion criteria for the targeted synthesis

\begin{tabular}{|c|c|c|}
\hline Inclusion criterion & Summary & Further details/explanation \\
\hline $\begin{array}{l}\text { 1. Research meets } \\
\text { basic scientific } \\
\text { standards }\end{array}$ & Must contain 'scientific research' & $\begin{array}{l}\text { This category comprised systematic } \\
\text { reviews, evaluations of interventions and } \\
\text { other scientific research. All qualifying } \\
\text { publications met basic scientific standards } \\
\text { in terms of methods and reporting and as } \\
\text { such provided a relatively strong and } \\
\text { reliable basis for synthesis. See Fig. } 2 \text { for } \\
\text { further explanation of how the different } \\
\text { types of enquiry were assessed. }\end{array}$ \\
\hline $\begin{array}{l}\text { 2. No double } \\
\text { counting }\end{array}$ & Must not be a systematic review & $\begin{array}{l}\text { To avoid double counting of evidence that } \\
\text { might skew the results, it is common } \\
\text { practice to exclude other systematic } \\
\text { reviews from synthesis and use instead any } \\
\text { of the original studies that qualify for } \\
\text { inclusion. }\end{array}$ \\
\hline
\end{tabular}

3. Focused results around European labour trafficking
Must contain disaggregated, extractable, substantive empirical evidence on European labour trafficking
In order to be of value to our synthesis, it was vital that we could extract from the publications empirical evidence specific to our research focus (European labour trafficking) rather than aggregate data combining this issue with other forms of trafficking and/or other geographies. We also used the requirement of substantiveness to decide whether a publication had sufficient relevant results to enrich the synthesis, rather than cluttering it for little added value. Due to the subjectivity around how much is enough to be substantiveness, any texts considered for exclusion on this basis were discussed by the review team. An illustrative example of a publication excluded on this basis was Gjermeni et al. (2008, p. 945), in which the sum total of results specific to European labour trafficking was the sentences: 'In terms of type of work, young children (ages 6-11) were engaged in begging while older youth were involved in theft, trade in drugs, street vending and prostitution. Boys were especially likely to be engaged in selling on the streets and begging'. 

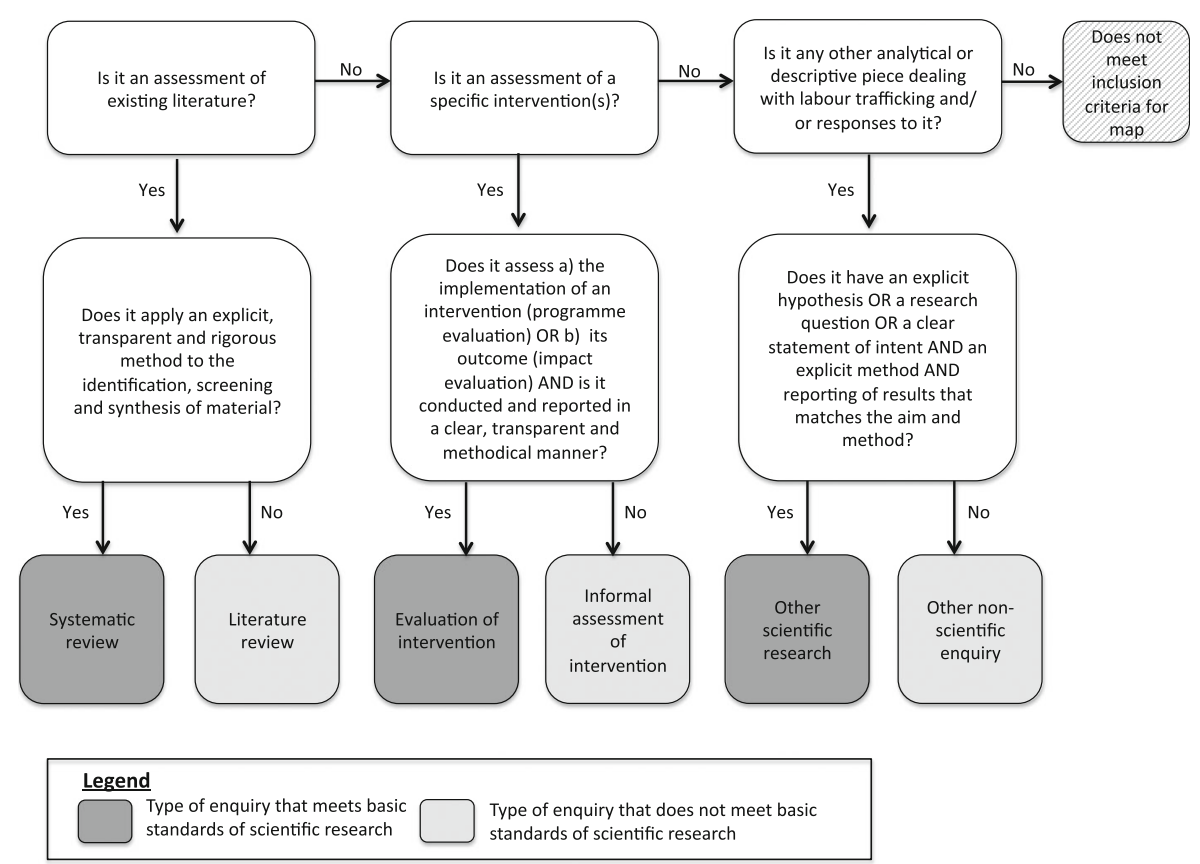

Fig. 2 Categorisation of different types of enquiry

Given the anticipated nature of the literature, we chose to assess the quality of the studies based on the best methodological approach possible under the circumstances of their designs, rather than the risk of bias inherent in these designs in the first place (for further discussion of the distinction between the two approaches, please see Liberati et al. 2009). Our quality assessment tool (Appendix 5) was based loosely on that from a systematic review of the health impacts of trafficking (Oram et al. 2012a). By rephrasing certain criteria and removing others, we simplified the original tool and made it applicable to a broader range of topics and methods. For example, we deleted the criterion 'Are the findings generalisable?' since generalisability is not something against which qualitative research is usually or reasonably assessed.

Two coders independently quality assessed each study. The results indicated a high level of inter-rater consistency: the rank order of the studies (based on total score) was the same and there was $88 \%$ overall agreement between coders. All discrepancies, none of which were larger than one point, were discussed and resolved.

\section{Results}

We present results from the systematic map and synthesis in turn. We use examples from publications to substantiate certain findings: these were selected for context and illustrative purposes and are neither exhaustive nor intended to 'name and shame'. Our coding was necessarily based on what was reported in the publications. It remains a possibility that at least some of the publications with underdeveloped or missing methods section were less methodologically weak in practice than in their reporting. 


\section{Phase 1: Systematic map}

The five key findings presented here together describe the overall state of the empirical evidence base on labour trafficking affecting Europe.

1. Although the empirical evidence base on labour trafficking is underdeveloped, the issue has been addressed in the context of numerous and diverse European countries

Despite the breadth of our map question, search strategies and inclusion criteria, we identified just 152 publications containing relevant empirical evidence on European labour trafficking (full bibliography in Appendix 6). There was no strong temporal trend in the production of evidence (see Fig. 3) but a slight skew towards later years: almost 70\% $(n=105)$ of publications appeared from January 2009 to July 2015 (approximately 40\% of the study period). During screening, we noted that certain countries' annual reports of human trafficking originally dealt exclusively with sex trafficking: in Sweden and the Netherlands, for example, labour trafficking was first included respectively in the ninth (National Criminal Police 2007) and fifth (Dettmeijer-Vermeulen et al. 2006) such reports.

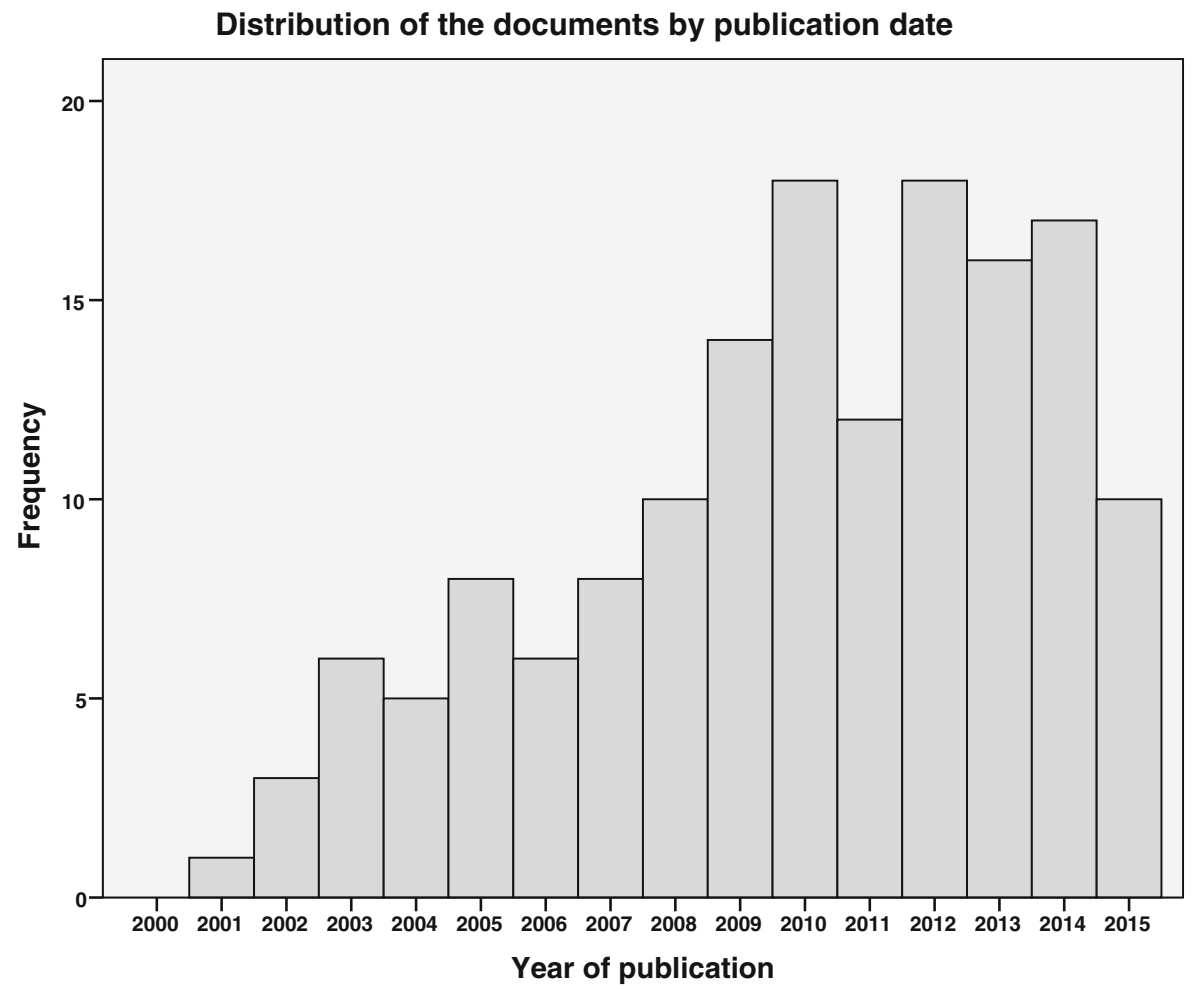

Fig. 3 Distribution of the documents by publication date 
Number of Publications by European Country

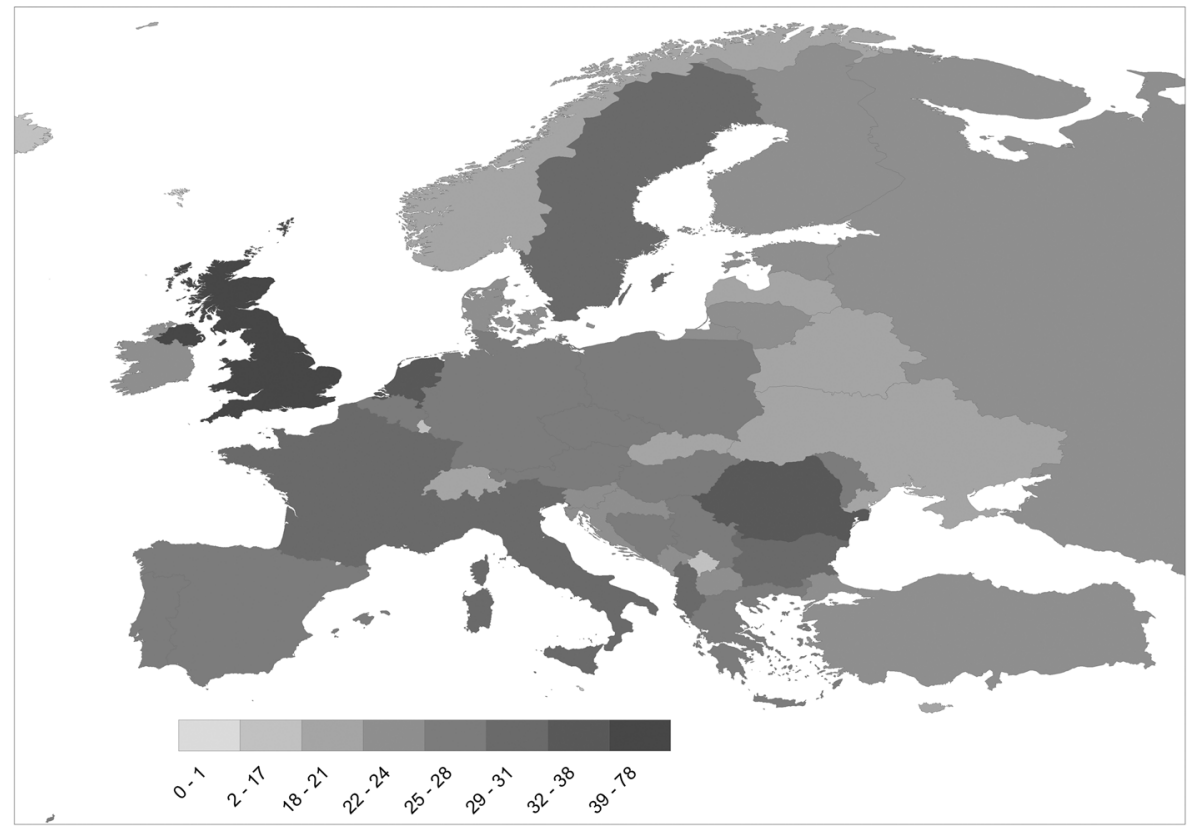

Fig. 4 Number of publications by European country

The publications used data collected in and/or from a wide range of European countries, including both developed and transition states (see Fig. 4$)^{5}$. The geographical distribution of coverage within Europe was fairly even, with a median of 23 publications per country and an interquartile range of 7 (20-27). There were notable outliers at both ends: the UK featured 78 times and five countries (Andorra, Holy See, Lichtenstein, Monaco, San Marino) appeared only once or not at all.

Publications were split roughly evenly between those dealing with one country $(51 \%, n=78)$ and multiple countries $(49 \%, n=74)$. There were striking methodological gaps in $9 \%$ of publications $(n=13)$ around precisely which countries were covered in all or part of their enquiries. Finally, multiple-country enquiries generally dealt with each country in isolation and international comparative analyses were rare: notable exceptions include Rijken (2011) and Jokinen and Ollus (2011).

\footnotetext{
${ }_{5}^{5}$ Eight publications do not feature in this figure: three covered no longer existing countries (Federal Republic of Yugoslavia and Former Federal Republic of Yugoslavia) and five did not specifically cover any European countries. Those not covering any European countries as an explicit source of primary or secondary data nonetheless met the inclusion parameters as they featured empirical data on victims who were themselves from Europe (e.g. Eastern Europeans trafficked to the United States for labour exploitation).
} 


\section{Authorship of the publications}

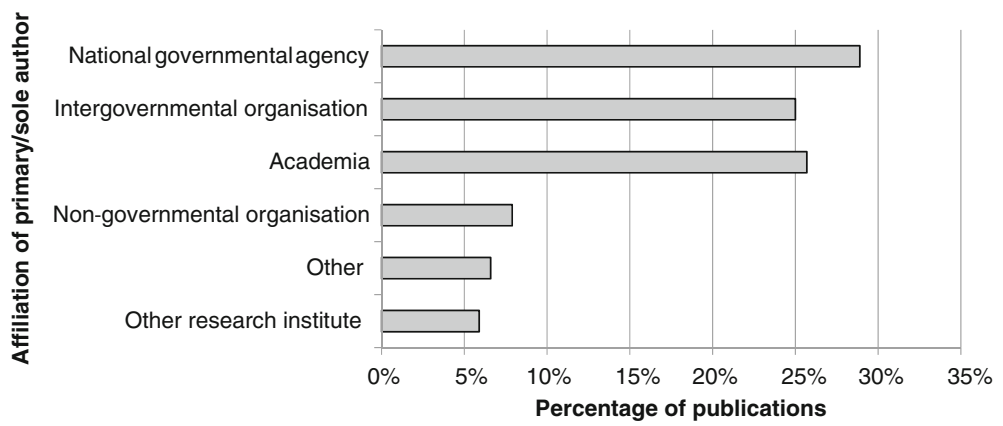

Fig. 5 Authorship of the publications

2. Reports dominate the literature and official agencies produce much of the evidence

There were remarkably few journal articles in the sample: just $12 \%(n=18)$. Reports were by far the most common publication format, accounting for $77 \%$ $(n=117)$ of the sample. The remainder was comprised of books or book chapters $(5 \%, n=8)$, theses $(1 \%, n=2)$ and miscellaneous formats $(5 \%, n=7)$. We noted that reports were often extremely long: the median was 84 pages (interquartile range of 112) and the longest ran to 644 pages.

A related issue was publication in non-indexed locations; although the database searches yielded the vast majority of our initial results $(87 \%, n=$ $5340)$, they contributed just $25 \%(n=38)$ of the publications mapped. Most (74\%, $n=113$ ) came instead from backwards searches, snowballing and requests to stakeholders.

To understand more about which agencies shape the trafficking knowledge base, we assessed documents' authorship (Fig. 5). Just $26 \%$ of publications came from academia, compared to $54 \%$ from governmental and intergovernmental agencies combined.

3. There is a striking lack of scientific research

Figure 6 shows the proportion of publications to contain each of the different types of enquiry. These modes of enquiry were not mutually exclusive; indeed almost a third of publications $(31 \%, n=47)$ featured the combination of a literature review and other non-scientific enquiry.

Only $12 \% \quad(n=18)$ of publications contained anything that met our definition of scientific research, despite the standards for this being fairly rudimentary (see Fig. 2). Of course, not all publications in the map were presented as containing 'research': for example, many summaries of administrative data produced by law enforcement agencies were not (e.g. National Crime Agency 2015; National Criminal Police 2007; National Police Board 2009, 2010, 2011, 2012; Serious Organised Crime Agency 2011). Numerous publications were, however, explicitly framed as research yet lacked the basic characteristics of scientific enquiry; examples with academic authors included Degirmencioglu et al. (2008), Oude Breuil (2008), Pearce et al. 
Types of enquiry featured in the publications

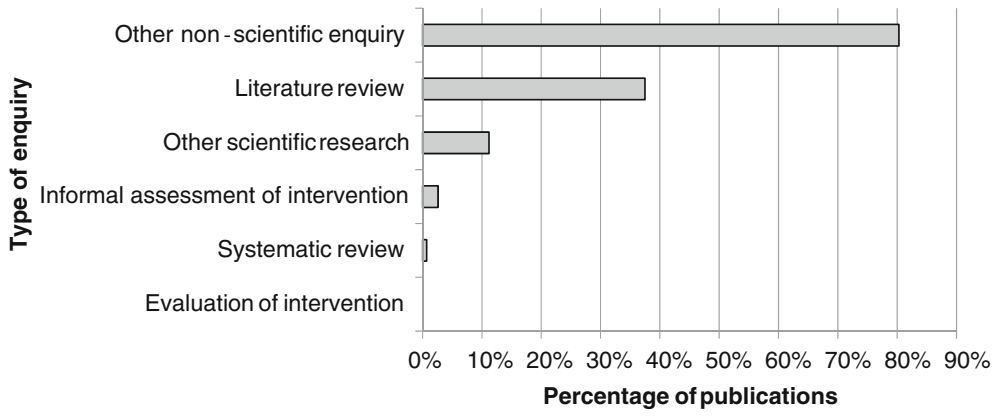

Fig. 6 Types of enquiry featured in the publications

(2009) and Ryazantsev et al. (2015). Such issues were also found in reports from official agencies. A key example was the U.S. State Department's Trafficking in Persons Reports, an influential series of publications. The extremely limited and vague information on methods, data and analysis they contained sat uneasily with their bold claims about 'a rigorous methodology' (U.S. Department of State 2001), data from 'credible reporting' (U.S. Department of State 2001, 2002, 2003) and being the 'gold standard' in assessing anti-trafficking responses (U.S. Department of State 2013).

Insufficient methodological transparency and a lack of analytical rigour were common shortcomings in the mapped publications. Examples include a methods section that merely listed data sources (Organization for Security and Co-operation in Europe 2014) and an interview-based study that did not report on the number of participants, their characteristics or the questions asked (International Centre for Migration Policy Development 2010b). Another frequent issue was inferences based on weak or inappropriate evidence, for example, generalisations exceeding what could reasonably be concluded from the methods and data (Anti-Slavery International 2014) or unsubstantiated claims of causality (Equality and Human Rights Commission 2011).

4. Qualitative approaches far outweigh quantitative ones

Far more of the publications were exclusively qualitative $(43 \%, n=65)$ in design than exclusively quantitative $(15 \%, n=22)$. Although mixed methods enquiries were common $(32 \%, n=49)$, within them, qualitative methods dominated and the quantitative contribution rarely exceeded the description of basic numerical data. Again highlighting the methodological weaknesses of the overall evidence base, $11 \%(n=16)$ of publications contained insufficient information even to establish whether the design was qualitative, quantitative or both.

5. There are major gaps in coverage around the impacts of labour trafficking itself and counter-measures 
Publications frequently contained a description of the problem profile of labour trafficking $(89 \%, n=135)$ and/or a discussion of interventions $(66 \%$, $n=98) .{ }^{6}$ Yet, very few included assessments of the impacts of either labour trafficking $(7 \%, n=10)$ or of interventions $(3 \%, n=4)$. Five of those that assessed labour trafficking's impacts met our criteria for scientific research, including a small but noteworthy set of studies addressing health impacts (Oram et al. 2012a, b; Turner-Moss et al. 2014). Publications involving assessments of interventions, none of which met our criteria for a scientific evaluation, focused either on victims' perceptions of interventions (International Centre for Migration Policy Development 2007, 2010a) or practitioners' perceptions of barriers to interventions (The Anti-Trafficking Monitoring Group 2010, 2012).

\section{Phase 2: Detailed synthesis}

We synthesised eight studies identified as key scientific research evidence on European labour trafficking. We report here on the studies' design (Table 4) and their key findings, conclusions and recommendations (Table 5). Table 5 also includes the studies' overall quality assessment scores and some general comments on the strength of the evidence they contain. Appendix 7 contains a full breakdown of their scores across the quality assessment criteria.

For multi-country studies, we detail the overall samples from European countries and, unless explicitly stated otherwise, findings and conclusions relate to all European countries involved. Some of the synthesised studies also included data, methods and/or topics outside our review's stated remit: for example, Rijken (2011) contained an analysis of policy and law around labour trafficking and UNICEF and Save the Children Norway (2002) had a distinct component addressing child sex trafficking. In such cases, we report only on those elements of the studies concerned with empirical evidence on European labour trafficking.

To complement the results at individual study level, we now consider some overarching findings about the synthesised studies' design, quality and contents.

1. There were some commonalities in design

First, all eight synthesised studies were exploratory in design, reflected in broad and inclusive foci and a predominance of descriptive research. The two studies into trafficking's health impacts (Oram et al. 2012b; Turner-Moss et al. 2014) were, however, notably more focused than the others in their questions, methods and analysis.

Second, all studies used non-random sampling. This is particularly noteworthy for those studies involving quantitative enquiries $(n=4)$ since it limits their external validity.

\footnotetext{
${ }^{6}$ These categories were not mutually exclusive so percentages do not sum to $100 \%$.
} 
Third, certain methods were especially common: semi-structured interviews and analyses of case records were used in five studies apiece.

Fourth, there were some commonalities in definitional approaches. Six of the eight studies defined human trafficking with explicit reference to the 'Palermo Protocol' (United Nations 2000); the two exceptions (Antal and Laszlo 2015; UNICEF and Save the Children Norway 2002) gave no definition. Three studies focused on the same specific sub-set of labour trafficking: begging/street work (Gavra and Tudor 2015; Tamas et al. 2013; UNICEF and Save the Children Norway 2002). The other five dealt with labour trafficking as a broad category (Antal and Laszlo 2015; Jokinen and Ollus 2011; Oram et al. 2012b; Rijken 2011; Turner-Moss et al. 2014). Of the latter, none provided an explicit definition of labour trafficking but all bar one (Antal and Laszlo 2015) implicitly counted domestic servitude as a form thereof.

2. The quality of evidence varied but was often low

All eight studies met our rudimentary criteria for scientific research applied at the mapping stage. The detailed quality assessment exercise highlighted enormous variation between the studies in terms of their overall calibre, which has obvious implications for the strength of the evidence they contain. Scores out of 18 ranged from a low of 2 (Gavra and Tudor 2015) to a high of 17 (Oram et al. 2012b). The overall quality was low: just three studies scored $50 \%$ or higher on the quality assessment. The two top-scoring publications stood out for their methodological transparency and rigour, frank discussion of limitations and clear and concise reporting (Oram et al. 2012b; Turner-Moss et al. 2014).

At the other end of the spectrum, low scores were often driven by methods reporting that was disjointed, inadequate and opaque, or, in some cases (Gavra and Tudor 2015; Rijken 2011), virtually non-existent. Methodological weaknesses included contradictory information (Tamas et al. 2013); missing information on fundamentals like sample size (Rijken 2011; UNICEF and Save the Children Norway 2002); and incoherence, with key methods information scattered across sections including results (UNICEF and Save the Children Norway 2002). Other drivers of low scores were unclear or imprecise reporting of results and the presentation of conclusions that had little to no grounding in the study data. Illustrative examples include not specifying the empirical basis for various findings despite using multiple methods and datasets (Tamas et al. 2013; UNICEF and Save the Children Norway 2002), and overextending results through presentation that exaggerated their generalisability (Gavra and Tudor 2015; Jokinen and Ollus 2011; Tamas et al. 2013; UNICEF and Save the Children Norway 2002). Taken to the extreme, in one publication, a single case study was framed as representative of an entire country's trafficking problem (Gavra and Tudor 2015). 
3. There were some common themes around labour trafficking and responses to it

Despite differences in the studies' foci and design, we identified common themes in their results and conclusions. In reading these findings, readers should be mindful of the variable quality of the original studies.

a. Responses to labour trafficking vary between countries but are generally seen as inadequate

There was considerable variation between specific European countries in terms of how they conceptualise and respond to labour trafficking and levels of awareness of the problem (Jokinen and Ollus 2011; Rijken 2011). Existing counter-trafficking measures were seen to be too heavily focused on sex trafficking at the expense of labour trafficking (Antal and Laszlo 2015; Jokinen and Ollus 2011; Oram et al. 2012b; Rijken 2011). Current responses to labour trafficking (either in general or for begging/ street work in particular) were perceived to be inadequate, including in respect to victim identification, service provision, law enforcement and preventative activity (Antal and Laszlo 2015; Gavra and Tudor 2015; Jokinen and Ollus 2011; Oram et al. 2012b; Rijken 2011; Tamas et al. 2013; UNICEF and Save the Children Norway 2002);

b. Labour trafficking affects diverse sectors and there may be spatial, temporal and sociodemographic trends to consider

As well as begging and street work (Gavra and Tudor 2015; Tamas et al. 2013; UNICEF and Save the Children Norway 2002), other sectors identified as affected by labour trafficking include food-processing, agriculture, restaurants, nail bars and car washes (Antal and Laszlo 2015; Jokinen and Ollus 2011; Oram et al. 2012b; Rijken 2011; TurnerMoss et al. 2014).

In terms of spatial, temporal and socio-demographic trends in labour trafficking, there were limits to what could be concluded - especially beyond the level of individual studies. There was evidence to suggest the industries in which labour trafficking is most commonly encountered vary by country (Jokinen and Ollus 2011; Rijken 2011), likely reflecting differences in local labour markets. Temporal patterns were hinted at where labour trafficking affected seasonal industries (e.g. fruit picking) (Jokinen and Ollus 2011). There were also indications that different types of victims may be preferred in different contexts. For example, trafficking of children and/or adults for begging was not associated with a pronounced gender imbalance (perceived or actual) (Gavra and Tudor 2015; Tamas et al. 2013; UNICEF and Save the Children Norway 2002). In contrast, men were often reported to be at greater risk of labour trafficking in general than women (the reverse is true of sex trafficking) (Antal and Laszlo 2015; Jokinen and Ollus 2011; Rijken 2011) and study samples of adult labour trafficking victims were indeed predominantly male (Tamas et al. 2013; Turner-Moss et al. 2014).

Apart from gender, many individual-level characteristics reported to be linked with vulnerability to labour trafficking were related to 
marginalisation, for example, by merit of being Roma, very young or very old, impoverished, unemployed or working on the street, homeless, in or just out of the care system, an illegal immigrant, and/or disabled (unlike in most other work contexts, disabilities may be advantageous for begging) (Antal and Laszlo 2015; Gavra and Tudor 2015; Jokinen and Ollus 2011; Rijken 2011; Tamas et al. 2013; UNICEF and Save the Children Norway 2002).

c. Labour trafficking victims are poorly treated and commonly display signs of ill health

Labour trafficking victims were or were perceived to be subject to very poor living and working conditions and to be manipulated through diverse control mechanisms, including threats, violence, withholding pay, confiscation of documents and physical, social and linguistic isolation (Antal and Laszlo 2015; Gavra and Tudor 2015; Jokinen and Ollus 2011; Tamas et al. 2013; Turner-Moss et al. 2014). Symptoms of poor health were high among victims of labour trafficking who accessed support services (Oram et al. 2012b; Turner-Moss et al. 2014). TurnerMoss et al. (2014) found the most commonly reported symptoms of poor physical health were headaches, back pain, fatigue, loss of appetite, toothache or mouth/gum problems, and eye pain, injury or difficulty seeing. They also found high rates of reporting of symptoms of posttraumatic stress, depression and anxiety.

d. Numerous barriers are seen to impede attempts to tackle labour trafficking

Numerous and diverse barriers to tackling labour trafficking were reported, including inadequate resourcing, limited awareness, unmet training needs, insufficient information sharing, ineffective collaboration, corruption and confusion around what constitutes labour trafficking in the first place (Antal and Laszlo 2015; Gavra and Tudor 2015; Jokinen and Ollus 2011; Oram et al. 2012b; Rijken 2011; Tamas et al. 2013; Turner-Moss et al. 2014; UNICEF and Save the Children Norway 2002).

e. Labour trafficking is seen as a complex, multi-faceted issue requiring holistic responses

Labour trafficking was characterised as a complex problem that overlaps with numerous other important labour market issues like child labour, forced labour, illegal working, economic migration and occupational health (Antal and Laszlo 2015; Jokinen and Ollus 2011; Rijken 2011; Turner-Moss et al. 2014; UNICEF and Save the Children Norway 2002). It was suggested interventions would benefit from being more systematic and coordinated and better integrating related phenomena (Jokinen and Ollus 2011; UNICEF and Save the Children Norway 2002). In particular, it was argued that protective measures to support vulnerable and exploited individuals should not be contingent on the 'trafficking' label being applied: in practice it can be difficult to distinguish between 'labour trafficking' and other forms of forced and exploitative labour (Jokinen and Ollus 2011; UNICEF and Save the Children Norway 2002). 


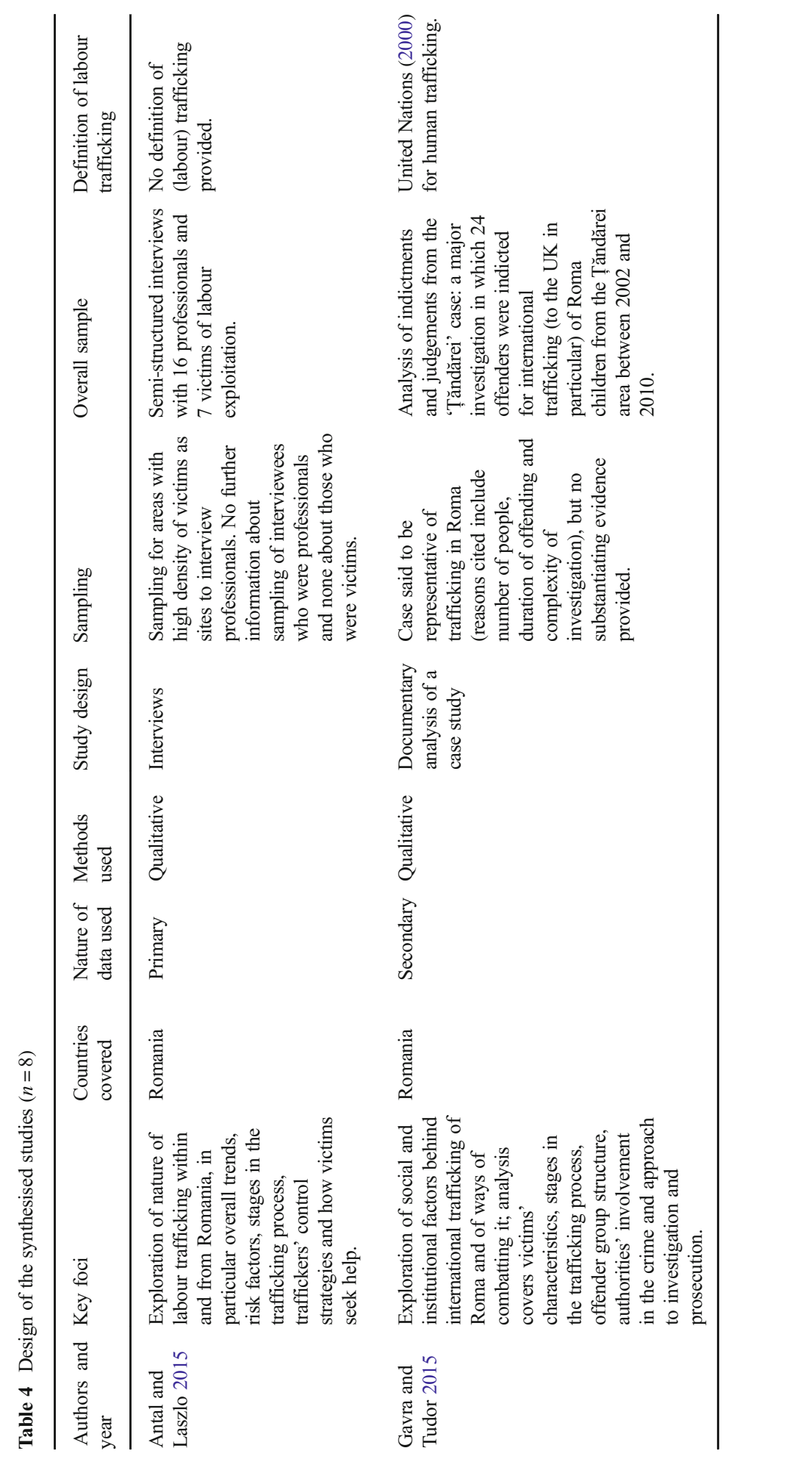




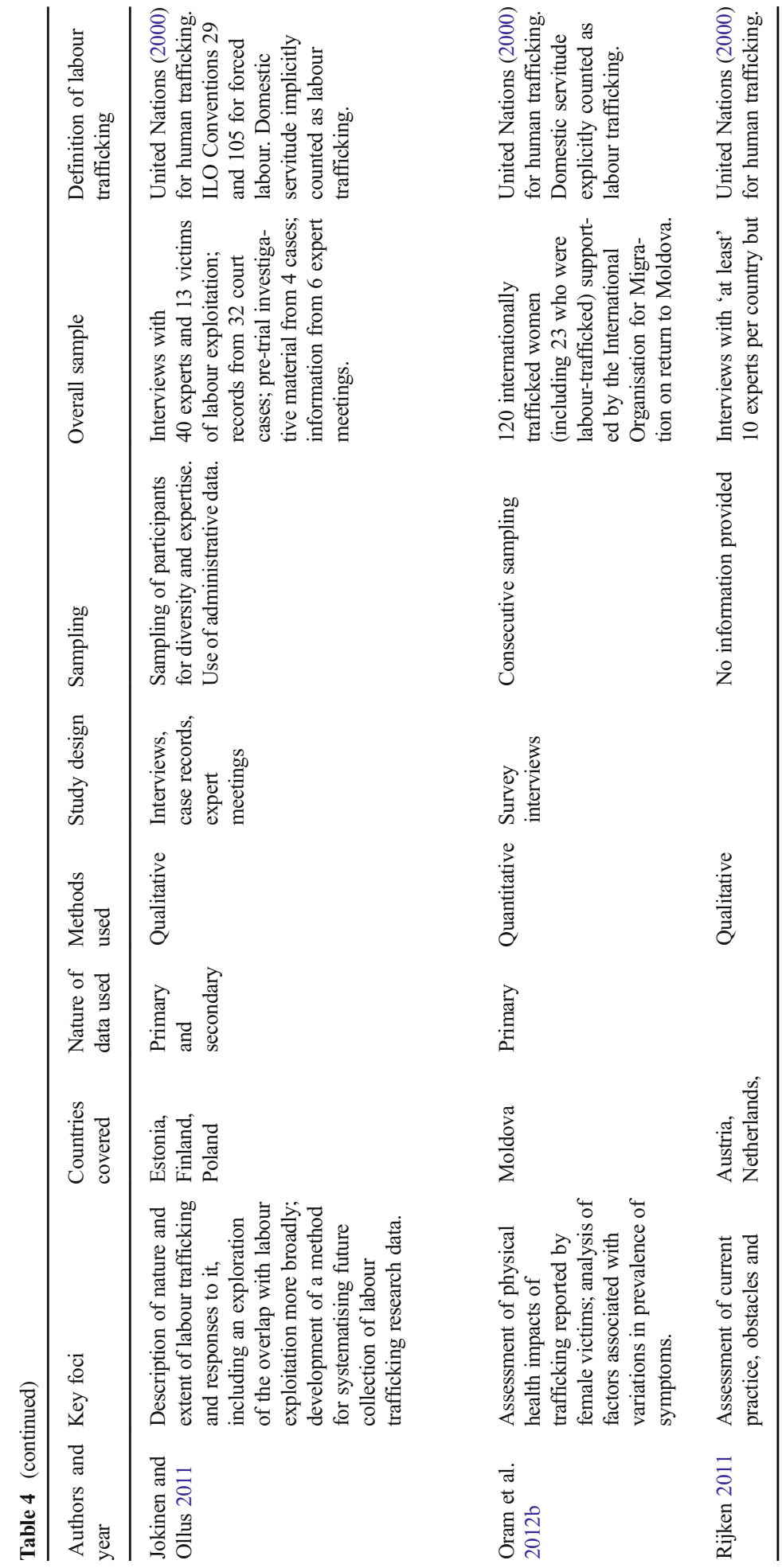




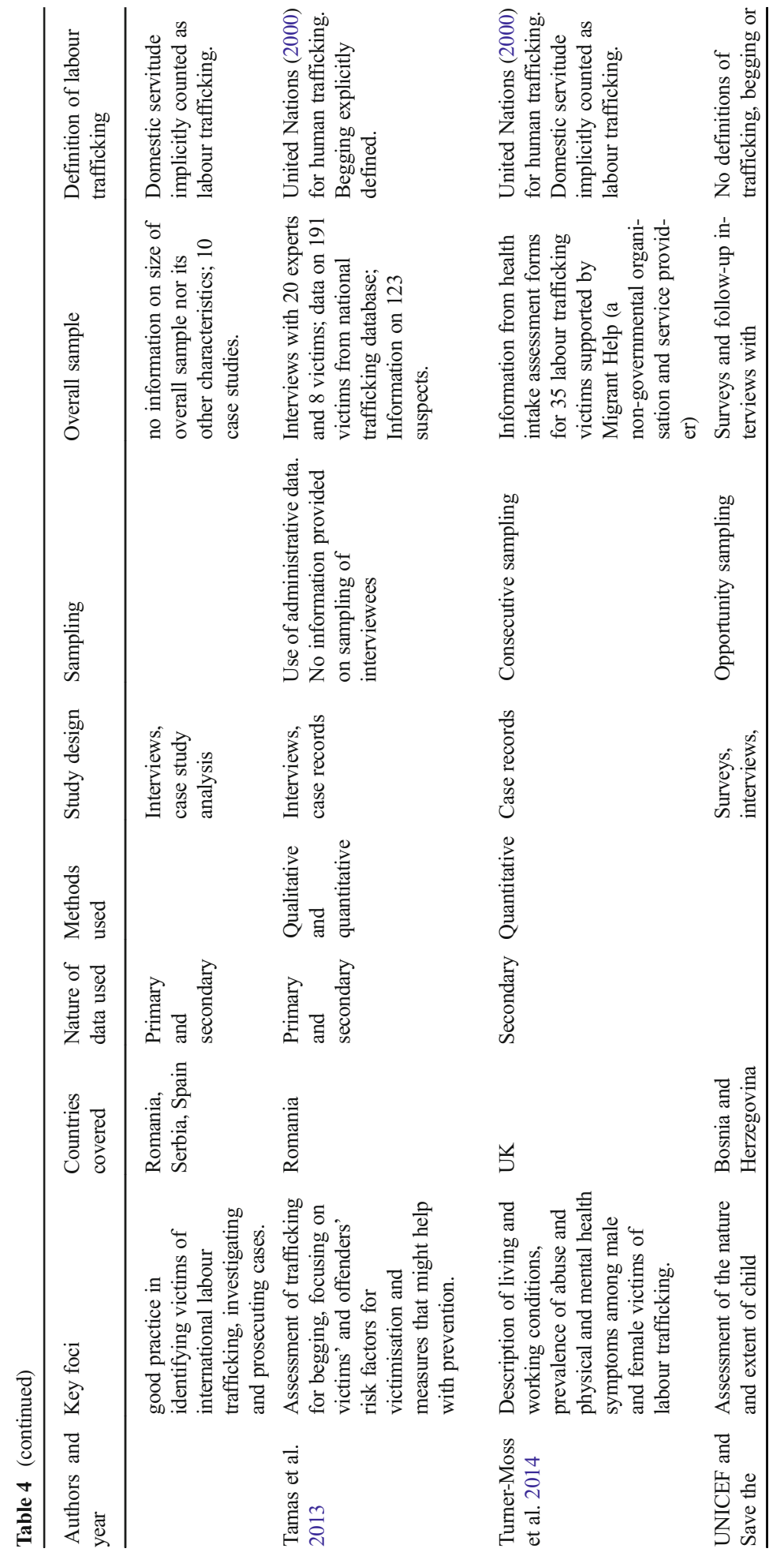




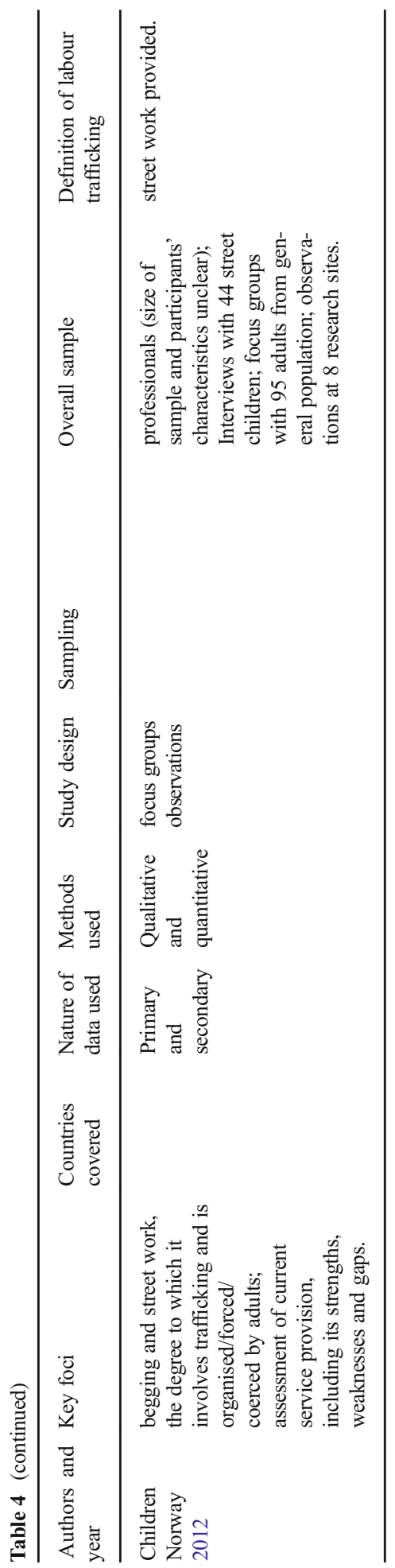




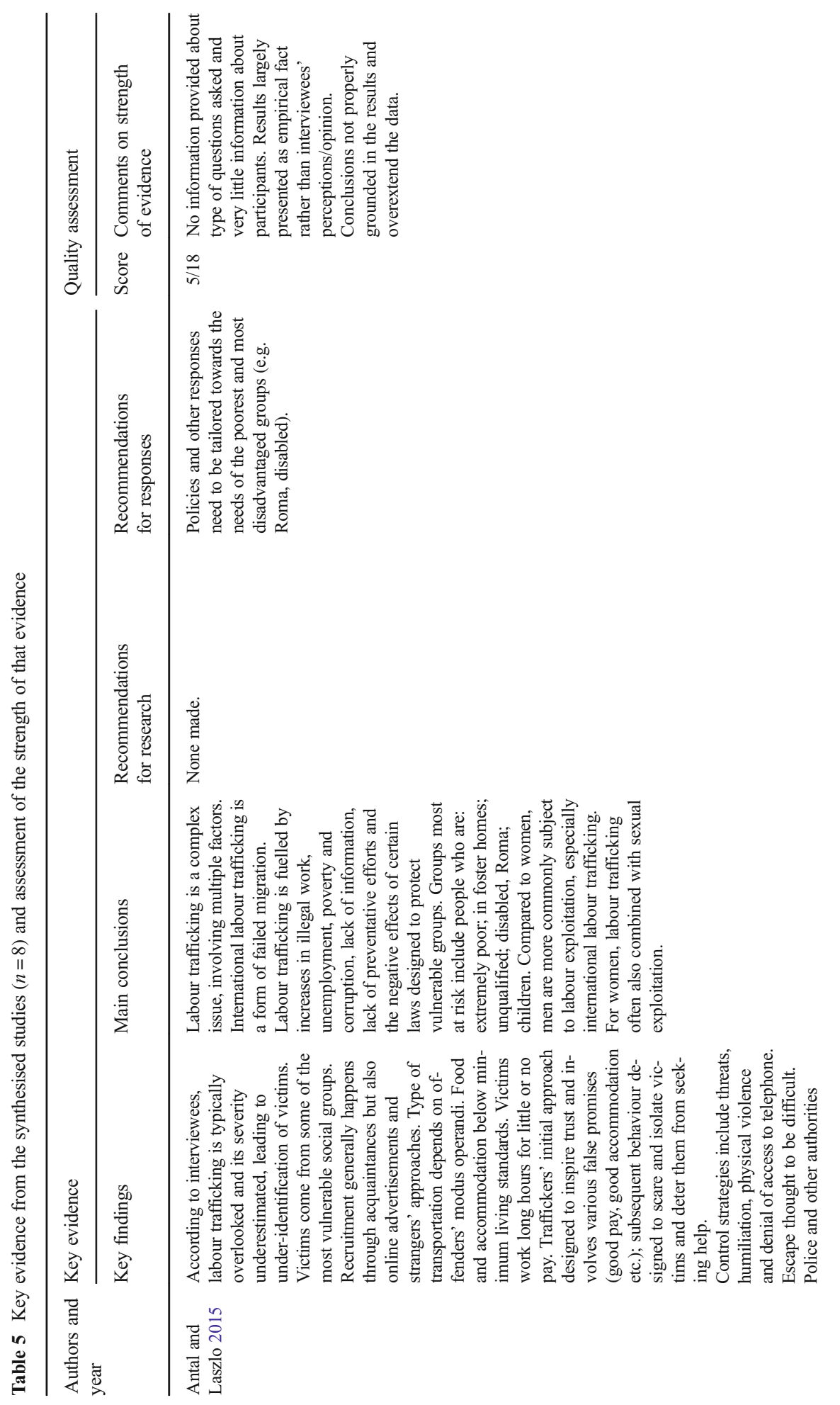




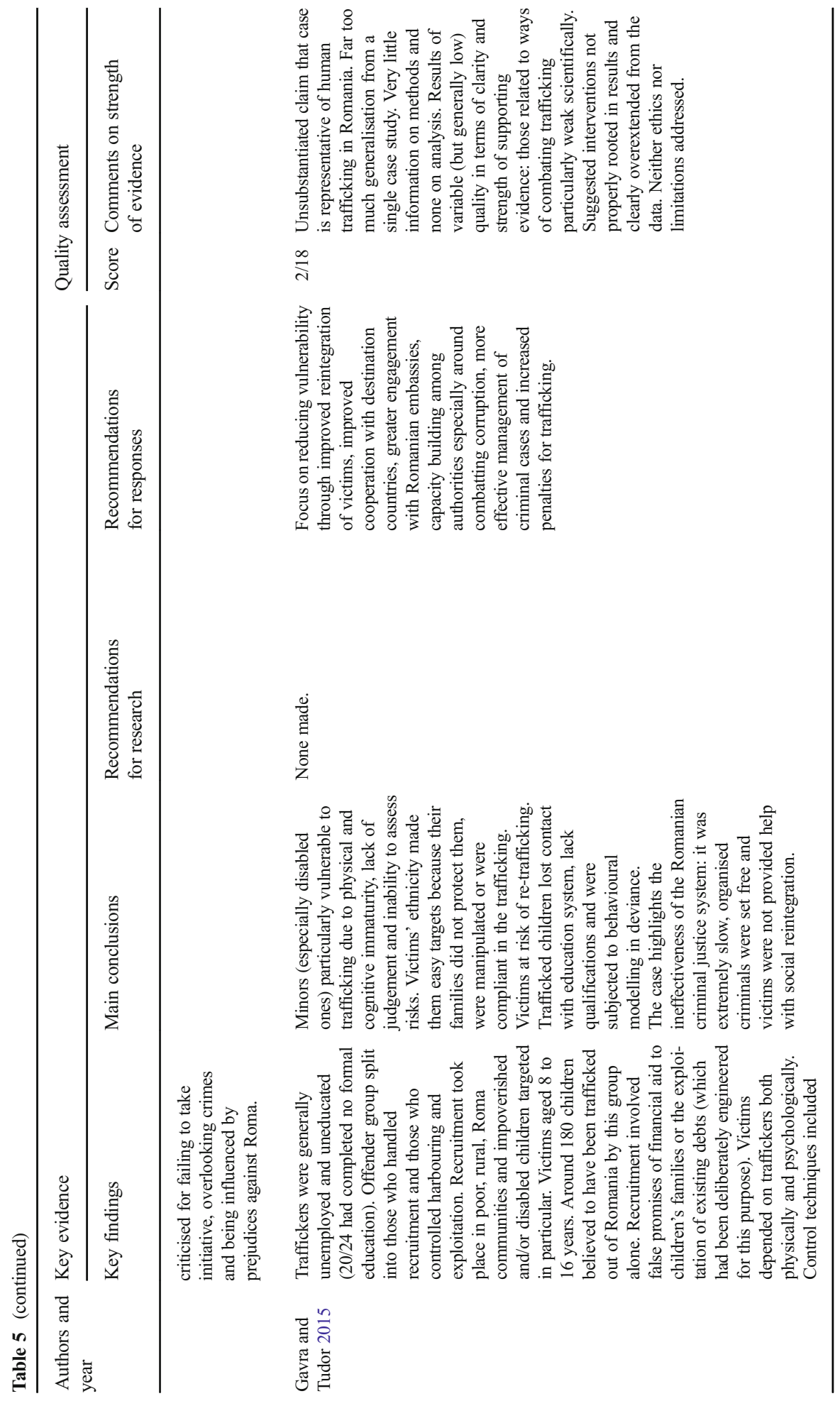




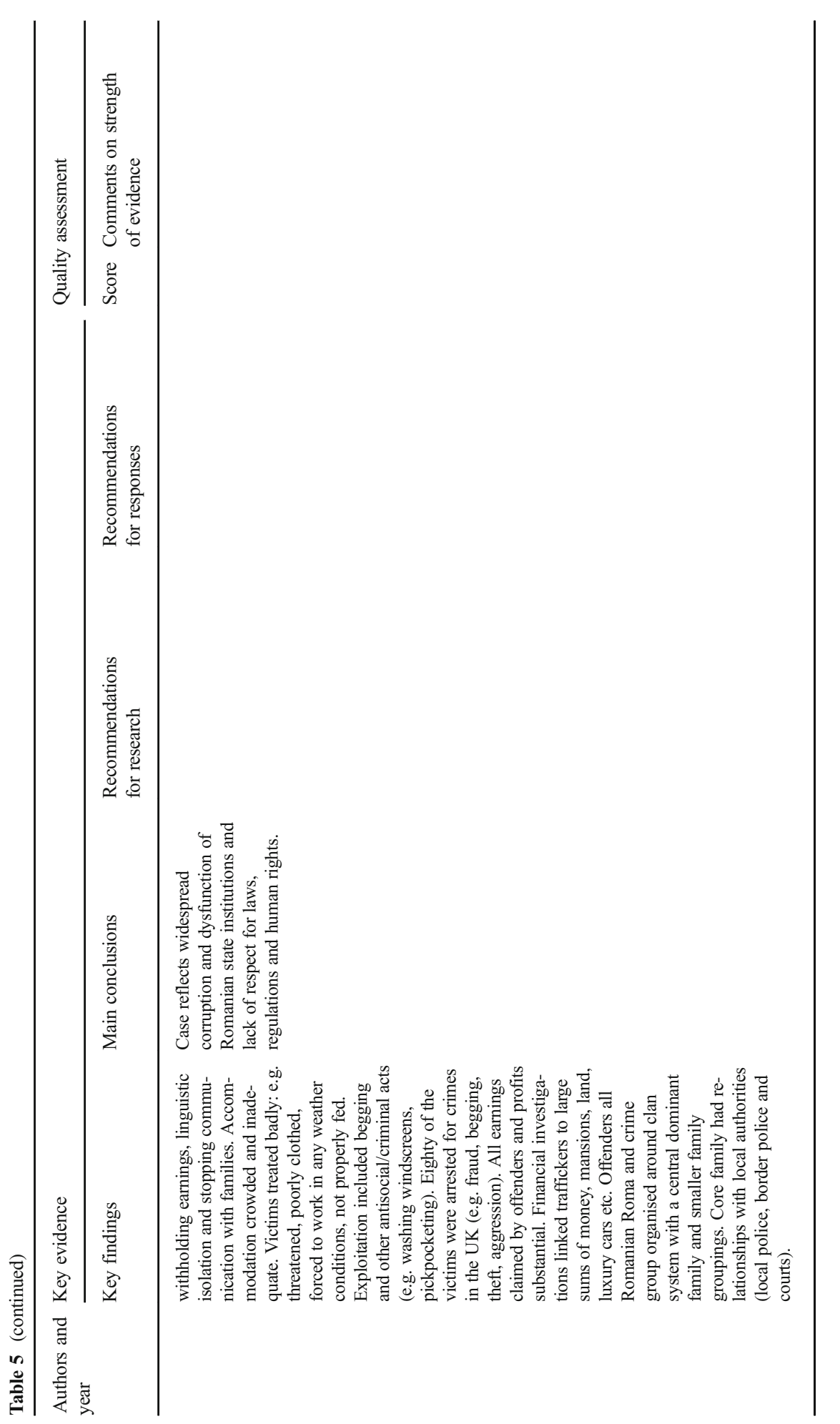




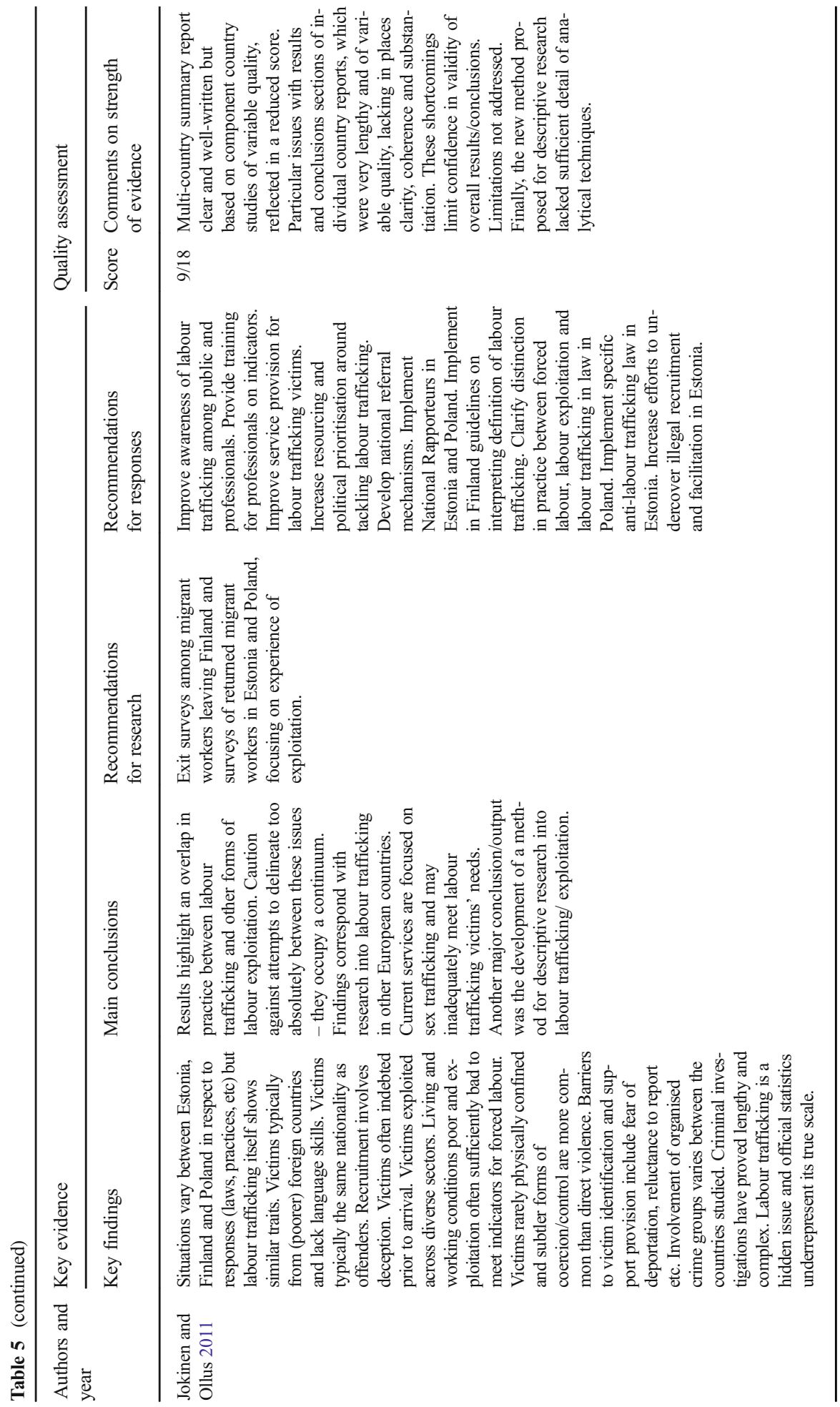




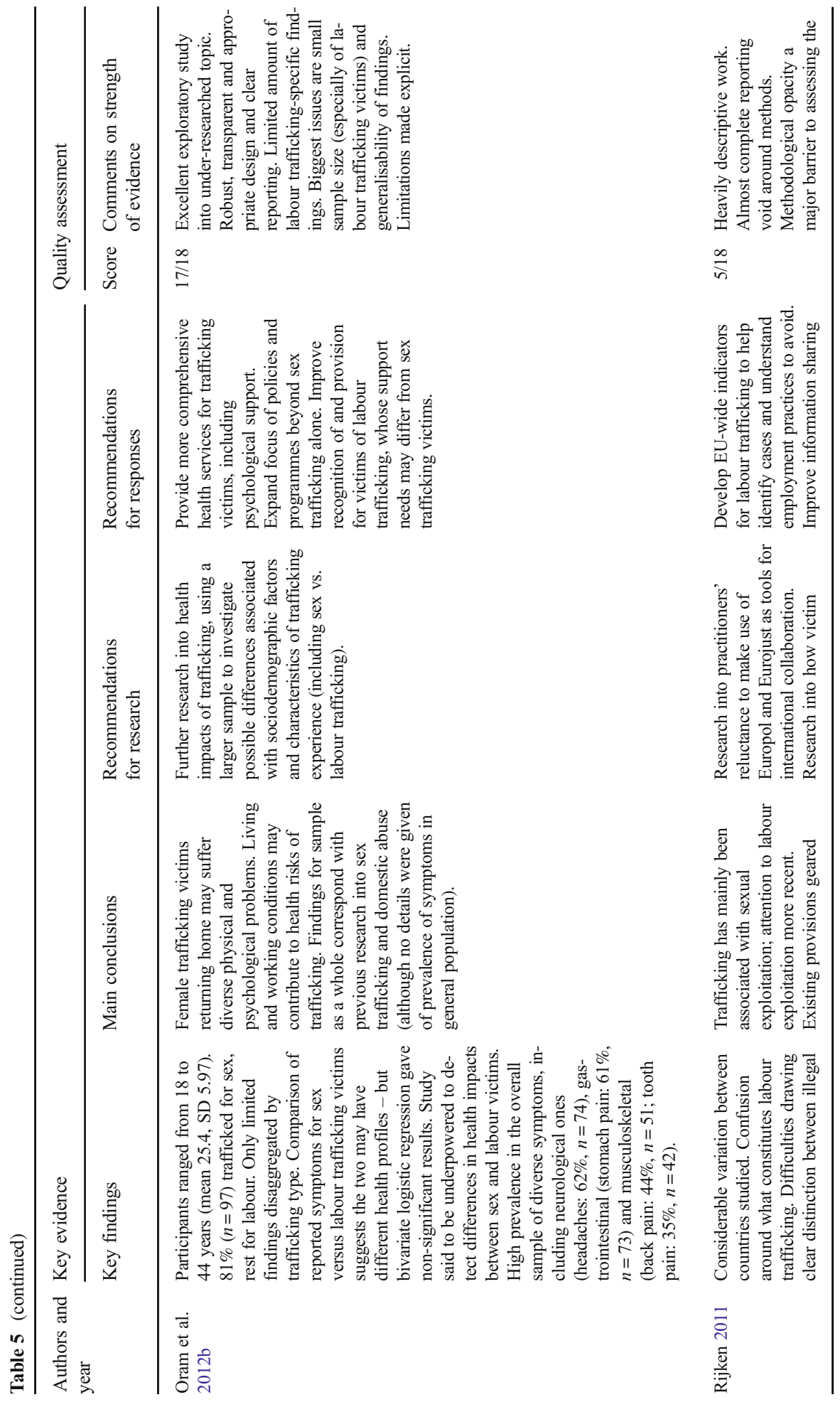




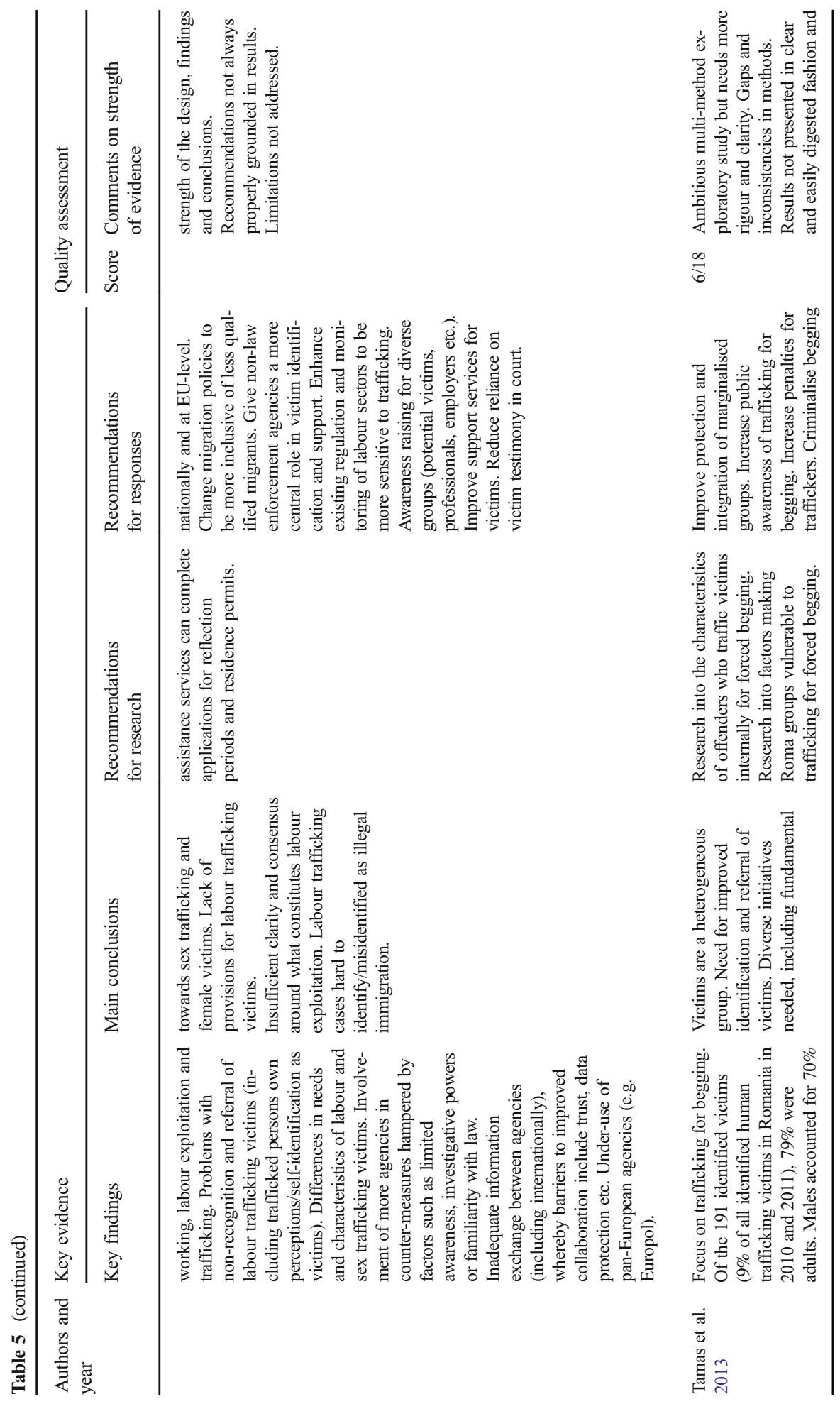




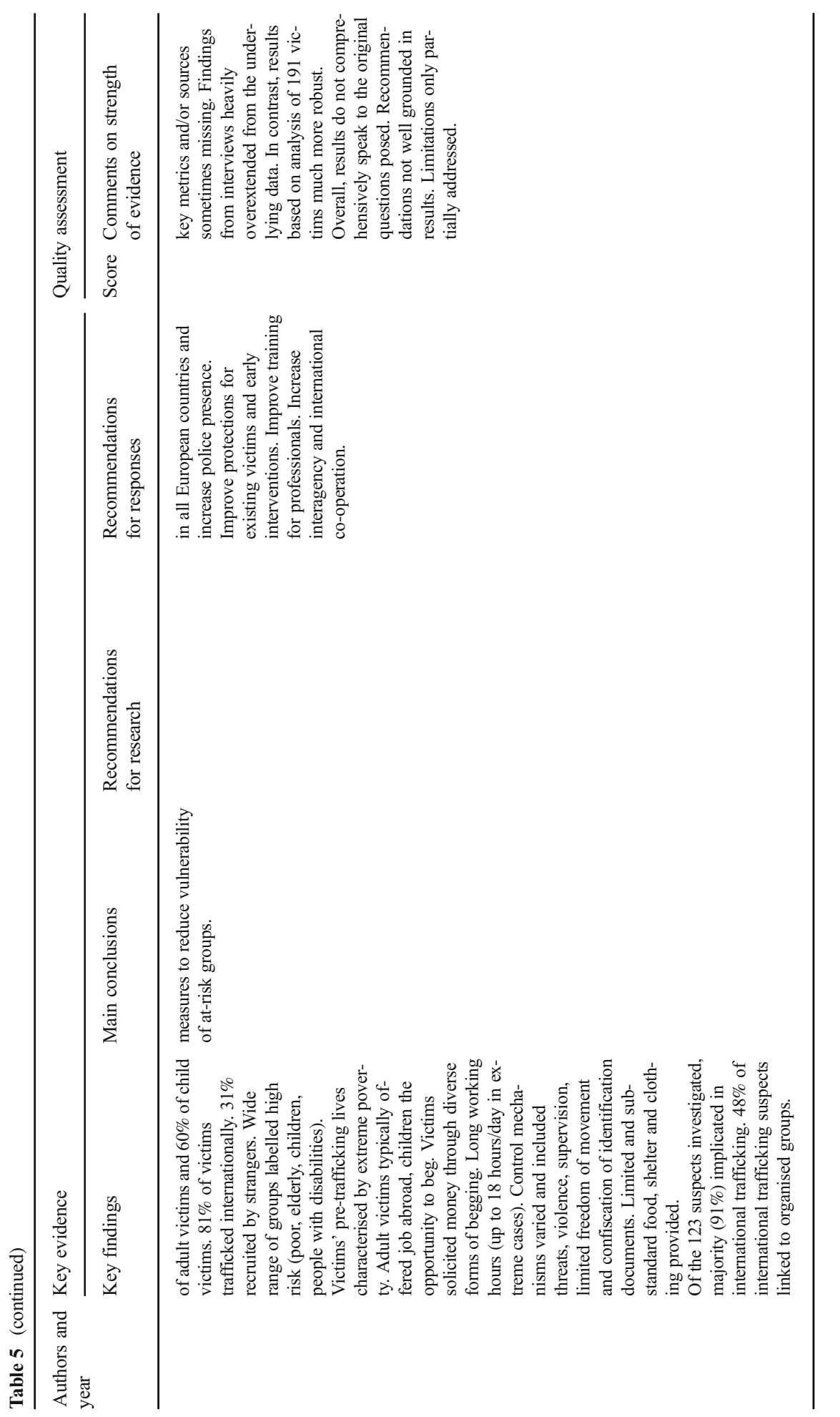




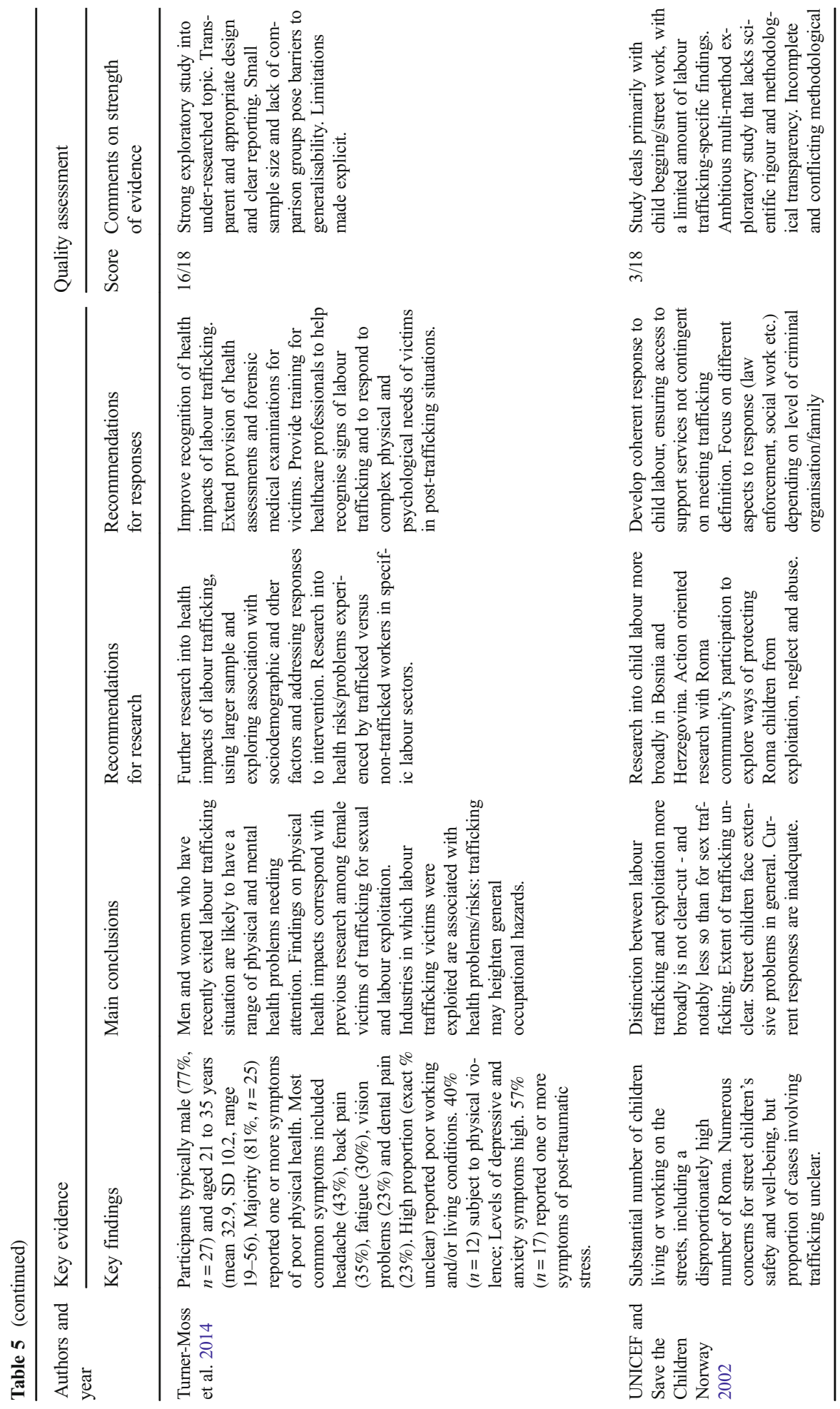




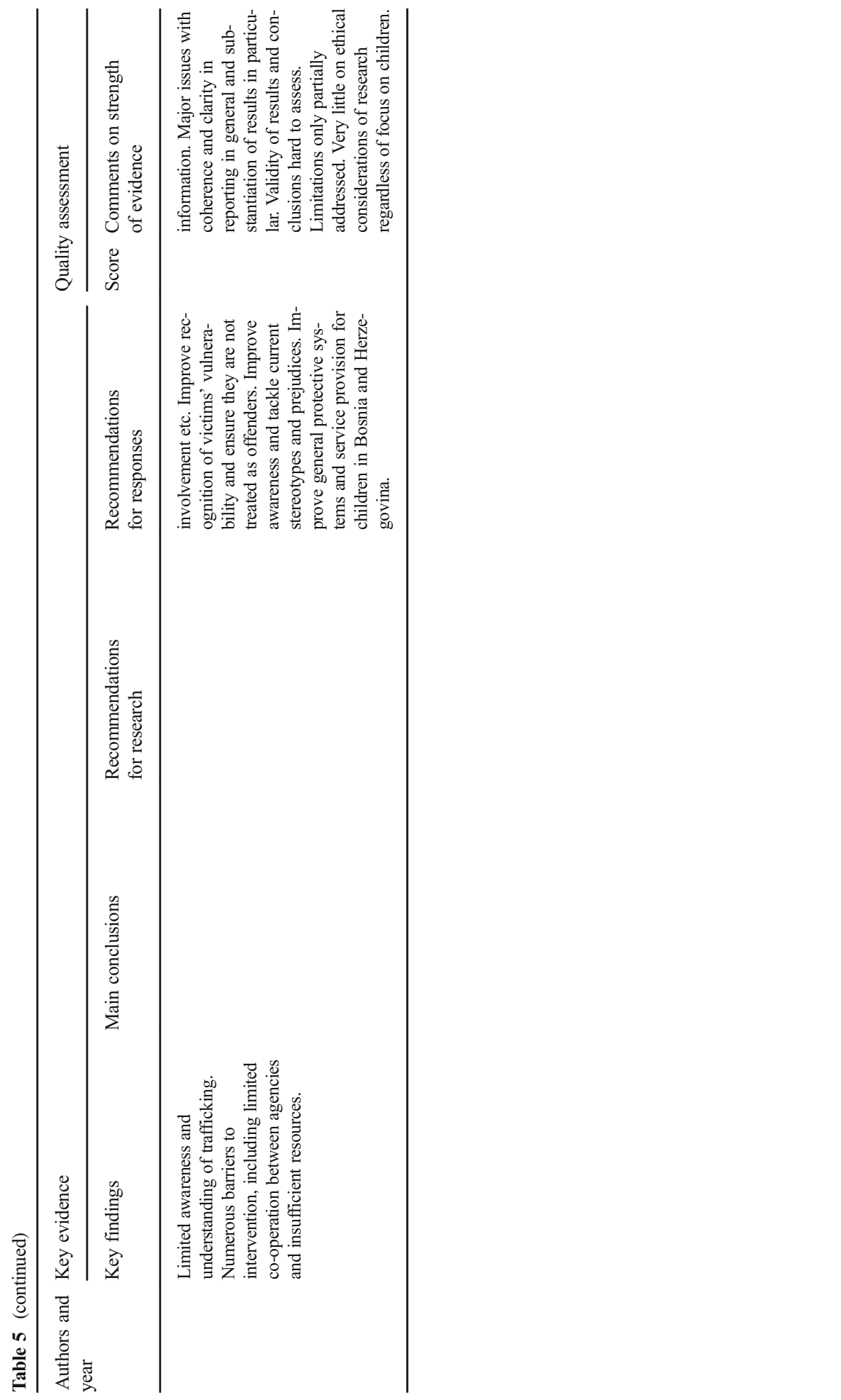




\section{Discussion}

We start by setting out the limitations of the study. We then discuss the results and implications for each of the mapping and synthesis stages in turn. Finally, we consider the review's overarching implications for future research into and responses to labour trafficking.

\section{Study limitations}

There were several potential sources of bias at the review level. First, restricting our review to publications in English may introduce language bias. English is said to be the lingua franca for trafficking research (Laczko and Thompson 2000). It was striking that we excluded just 26 publications for not being in English, accounting for less than $1 \%$ of overall exclusions.

Second, there may be publication bias or bias in the identification of studies. Systematic reviews are arguably more challenging in the social than medical sciences since there are more databases with lower indexing standards and publications in nonindexed locations play a greater role (qualitative research is generally less likely to be published in indexed locations) (Brunton et al. 2012; Thomas and Harden 2008). Research from developing countries may be less likely to be published in indexed journals (Zielinski 1995), possibly affecting in particular the coverage of some Eastern European countries in our review. As safeguards against such biases, we searched a broad range of databases (academic and grey literature) and also used diverse complementary search strategies (e.g. asking for recommendations from stakeholders from across Europe).

Third, there may be some coding bias. For clarity and transparency's sake, we include all coding frameworks in our appendices. Where we single-coded (screening and mapping stages), we made sure to pilot our codebooks, assess for inter-rater reliability (results showed good consistency) and encourage the coders to seek a second opinion where unsure. We double-coded the quality assessment of the studies in the synthesis. Some of the coding categories in the rest of the synthesis were open-ended and narrative in nature. Although unavoidable, as they are appropriate to the review of qualitative literature, such categories introduce greater subjectivity and with it a risk of bias. For validation and quality control, a second coder reviewed and commented on the main coder's outputs here.

\section{The systematic map}

Despite increased prioritisation of labour trafficking in European counter-trafficking policy and practice (de Jonge 2005; Eurostat 2013; Jokinen and Ollus 2013; National Police Board 2011; Organization for Security and Co-operation in Europe 2008; Rijken 2011), our results indicate that the evidence-base is underdeveloped: across a 15.5-year review period we found just 152 publications containing empirical data on European labour trafficking. Enquiries used primary and secondary data from a wide range of European countries. Although multi-country studies were common, robust comparative analyses were not, which may be inhibiting the development of a coherent European evidence base and contributing to duplication of research efforts. 
Comparability could be a contributory factor here due to variations in laws, definitions and available data even within European Union member states (de Jonge 2005; International Labour Office 2009; Organization for Security and Co-operation in Europe 2008; Rijken 2011).

While publication in a journal does not guarantee quality, the peer-review process is widely seen as a quality-control measure that promotes rigour and transparency. Yet, the majority of mapped publications were reports: a format that is generally neither well-indexed nor subject to rigorous quality control. The preponderance of grey literature raises concerns about the visibility, accessibility and quality of the evidence on labour trafficking. Digestibility is another consideration: the tendency towards very lengthy publications may limit their dissemination, consumption and, ultimately, impact.

The knowledge-production process was dominated by official agencies, with comparatively little input from academics and other independent parties. Of course, different authorships have different strengths. Robust outputs from practitioners, for example, can capitalise on valuable experiential knowledge and hardto-access data and sources. In contrast, obvious advantages to academic outputs include the expectation of impartiality, rigorous methods training, strong analytical skills and research experience. The scarcity of academic research may reflect difficulties in securing data access, an oft-cited barrier to trafficking research (Feingold 2010; Goodey 2008; Goździak 2008; Tyldum 2010).

The most disparaging feature of the evidence base was the overall lack of quality research on European labour trafficking. Just $12 \%(n=18)$ of mapped publications met our basic criteria for scientific research. It seems that the problem is less that there is too little information, although there are certainly major gaps, and more that so much of it risks being lost because it exists in states not conducive to meaningful appraisal and synthesis. Many publications that fell short of the inclusion criteria for our synthesis contained material that was interesting, empirically-rich and informative (e.g., Andrees 2008; Eurostat 2013, 2015; Migrant Rights Centre Ireland 2007; Surtees 2007, 2008, 2014). Yet, it is difficult to make good use of such information in a review when the methods by which it was originally obtained are weak or unclear.

The predominance of qualitative techniques may well be related to the evidence base's underdevelopment: less mature fields may gravitate towards exploratory enquiries for which qualitative methods may be optimum. It has also been argued that the quality and quantity of official datasets on labour trafficking are far lower than those on sex trafficking (the longstanding focus of counter-trafficking efforts) (International Labour Office 2009; International Organization for Migration 2010; Organization for Security and Co-operation in Europe 2008). There may also be a reluctance to use official data because of their biases (such as systematic under-reporting). Yet, if the evidence base on European labour trafficking is to progress, there is a also need for robust quantitative enquiries. The current scarcity of quality quantitative research leaves a void that risks being filled by dubious and unreliable statistics.

Numerous publications described the problem of labour trafficking and somewhat fewer the responses to it. Yet, few addressed the impacts of labour trafficking and fewer still the impacts of responses. Understanding the nature of the problem is an important first step, akin to the scanning stage in the SARA (scanning, analysis, response, assessment) model of problem-oriented policing (Eck and Spelman 1987). If the 
counter-trafficking field is to evolve, it is vital to evaluate the impacts of trafficking and of interventions. The fact that we found no scientific evaluations precludes any conclusions about 'what works' or 'best practice' in tackling European labour trafficking.

\section{The synthesis}

Traditionally, trafficking research and responses have focused heavily on sex trafficking and concerted interest in labour trafficking is fairly recent (Andrees and Linden 2005; Home Office 2007; Kelly 2005; Laczko and Gozdziak 2005; Surtees 2008). Indicative of the immaturity of the scientific research base on European labour trafficking, just eight studies qualified for inclusion in our synthesis and all bar one of them (UNICEF and Save the Children Norway 2002) were published after 2010.

In light of the literature's underdevelopment, it was unsurprising to find all the synthesised studies were exploratory and descriptive. All involved non-random sampling, too. Sampling for expertise and/or diversity is fairly standard practice when conducting expert interviews, which was a key method in five of the eight studies (Antal and Laszlo 2015; Jokinen and Ollus 2011; Rijken 2011; Tamas et al. 2013; UNICEF and Save the Children Norway 2002). Four of the eight studies were partially or fully quantitative in design, however (Oram et al. 2012b; Tamas et al. 2013; TurnerMoss et al. 2014; UNICEF and Save the Children Norway 2002) and in this context opportunity sampling clearly limits external validity. It should be emphasised though that traffickers and their victims are hidden populations; insufficient knowledge of their characteristics impedes the creation of reliable sampling frames (Tyldum and Brunovskis 2005). Additionally, trafficking is a high-severity, low-frequency crime (in contrast to 'volume crimes' like burglary) and to detect enough cases research samples of the general population might have to be prohibitively large.

Unlike in medicine (Shamseer et al. 2015), systematic reviews in criminology do not routinely include a quality assessment (Johnson et al. 2015). Our quality assessment exercise proved valuable in highlighting the variable strength of evidence (studies' scores ranged from 2 to 17 out of 18) and weak overall quality (5 out of 8 scored below $50 \%$ ). These results caution against reporting evidence in a review without also considering its strength. The two highest-scoring publications by far were also the only journal articles (Oram et al. 2012b; Turner-Moss et al. 2014), possibly reflecting the additional quality assurance the peer-review process can bring.

We found numerous weaknesses in the design, conduct and reporting of other studies in the synthesis: in particular, insufficient clarity and transparency around methods, overextending the data and not paying due consideration to limitations, and conclusions that were not well-grounded in the results. These thematic findings should be treated as preliminary rather than conclusive or exhaustive. Taken as a whole, they suggest that there is a clear and unmet need for improved responses to European labour trafficking, including around prevention, intervention, monitoring and victim support. The possibility of gendered differences in trafficking types (labour trafficking disproportionately affecting men) merits further attention. The severity of labour trafficking was reflected both in its association with symptoms of ill health and more general accounts of extremely poor living and working conditions. While it remains to be seen whether and how the experiences and impacts of labour trafficking diverge from, say, 
sex trafficking, these results speak to a clear need for investment in both support services for victims of labour trafficking and targeted preventative activity. Numerous perceived barriers to intervention were highlighted, ranging from limited awareness to unmet training needs and widespread corruption. While their actual impact was not assessed, it would be useful to consider these factors when designing and evaluating interventions. The results suggest labour trafficking can affect a diverse range of legal and illegal industries. A more differentiated approach to researching and responding to labour trafficking that takes into account similarities and differences between sectors could prove useful in future. Finally, the overlaps between labour trafficking and other labour market issues (child labour, economic migration, etc.) highlight the importance of situating research on and responses to labour trafficking within a broader spectrum of interrelated matters: labour trafficking should not be reduced to a criminal justice issue alone (see also Dutch National Rapporteur 2009; Esson 2015; Jokinen and Ollus 2011, 2013; Lewis et al. 2014; Skrivankova 2006; UNICEF and Save the Children Norway 2002).

\section{Overall implications for research and responses}

Our criticisms of the literature, in particular the low reporting standards, are not mere 'academic pedantry'. These shortcomings represent genuine barriers to building and advancing a strong evidence base. Many of our criticisms echo those made in previous (non-systematic) reviews of and commentaries on other aspects to the human trafficking literature. Similar complaints about methodological opacity, lack of rigour, failure to acknowledge and account for limitations and skews in focus and methods have been heard repeatedly for over a decade (Andrees and Linden 2005; Aronowitz 2009; Di Nicola 2007; Feingold 2010; Goodey 2008; Kelly 2005; Laczko 2005; Laczko and Gozdziak 2005; Tyldum and Brunovskis 2005). As Kelly (2005, p. 237) argued, the 'lack of methodological transparency provides little foundation for assessing the depth and quality of research and denies the entire field opportunities for learning and knowledge transfer.'

As labour trafficking continues to ascend the policy and practice agenda, greater investment in research and interventions will likely follow. It is imperative to avoid repeating previous mistakes, as despite considerable spending on measures to counter human trafficking (especially sex trafficking), responses have rarely been evidencebased and the literature remains notoriously weak (see, e.g., Gozdziak and Bump 2008). Based on our findings, we would particularly recommend the following measures. First, the commissioning of research to address particularly neglected areas, including the impacts of labour trafficking, evaluations of interventions and comparative analyses. Second, increased investment in research that is explanatory rather than purely descriptive; there is a particular need for strong quantitative research that exploits existing datasets or makes use of innovative new datasets. Third, increased academic involvement in empirical research, especially through collaborations between independent researchers and those who act as gatekeepers to data and participants. Finally, but most importantly, overall improvements in research design and reporting standards. This last recommendation is particularly critical as it applies to virtually any study. Although making such improvements is primarily the responsibility of individual researchers, funders and end-users can contribute by holding them to account. What 
constitutes 'good' research and reporting is to a certain extent dependent on specific disciplines and methods, but there are certainly common factors. Rather than reinvent the wheel, we refer readers to the quality assessment tool (Appendix 5): its nine questions provide a useful checklist for designing, reporting and critically consuming research. We would add one further point to the list: the provision of an explicit research definition of labour trafficking, including any inclusion/exclusion parameters and how it was operationalised. Otherwise, the lack of definitional clarity and consistency will remain a barrier to comparing studies.

\section{Conclusions}

Despite a marked increase in attention around labour trafficking in Europe, there is a scarcity of high-quality empirical evidence on the problem, its impacts and responses to it. Our review showed the evidence base to be limited, fragmented and subject to skews in thematic focus and methodological design. Few publications met even basic scientific standards and even those that did were of variable and often low quality. Particularly pronounced problems included a lack of methodological transparency and rigour, shortcomings that restrict what conclusions can be drawn from the literature.

Overall, our synthesis indicated that European labour trafficking is a complex and challenging problem to which current responses may be inadequate. The lack of a coherent and robust research base limits the feasibility of evidence-based policy and practice, which is a concern given the threats labour trafficking poses and the resources devoted to tackling it. Amid numerous knowledge gaps around European labour trafficking, it is vital to pay attention to increasing the quality of the evidence, not just the quantity.

Acknowledgements We would like to thank the stakeholders for their valuable input into the review. We are also very grateful to our colleagues at UCL, Lisa Tompson, Aiden Sidebottom, Shane Johnson, Jyoti Belur and Amy Thornton, for sharing their ideas, experiences and feedback. We also greatly appreciated the many insightful comments and suggestions on our earlier drafts from the editor and anonymous reviewers. This study was funded by the Economic and Social Research Council of the UK (ESRC), through the 'Future Research Leaders' fellowship scheme (grant reference: ES/K008463/1).

Open Access This article is distributed under the terms of the Creative Commons Attribution 4.0 International License (http://creativecommons.org/licenses/by/4.0/), which permits unrestricted use, distribution, and reproduction in any medium, provided you give appropriate credit to the original author(s) and the source, provide a link to the Creative Commons license, and indicate if changes were made.

\section{References}

Andrees, B. (2008). Forced labour and trafficking in Europe: how people are trapped in, live through and come out. Geneva: International Labour Office.

Andrees, B., \& Linden, M. N. J. (2005). Designing Trafficking Research from a Labour Market Perspective: The ILO Experience1. International Migration, 43(1-2), 55-73.

Andrees, B., \& van der Linden, M. N. J. (2005). Designing Trafficking Research from a Labour Market Perspective: The ILO Experience1. International Migration, 43(1-2), 55-73. 
Antal, I., \& Laszlo, E. (2015). The Situation of Human Trafficking for Labour Exploitation in Romania. Paper presented at the 2nd International Multidisciplinary Scientific Conference on Social Sciences and Arts, Albena.

Anti-Slavery International. (2014). Trafficking for forced criminal activities and begging in Europe: exploratory study and good practice examples. London: Anti-Slavery International.

Aronowitz, A. A. (2001). Smuggling and trafficking in human beings: the phenomenon, the markets that drive it and the organisations that promote it. European Journal on Criminal Policy and Research, 9(2), 163195.

Aronowitz, A. A. (2009). Human trafficking, human misery: the global trade in human beings. Plymouth: The Scarecrow Press.

Belser, P. (2005). Forced labour and human trafficking: Estimating the profits. Geneva: International Labour Organization.

Belser, P., de Cock, M., \& Mehran, F. (2005). ILO Minimum Estimate of Forced Labour in the World. Geneva: International Labour Organization.

Brunton, G., Stansfield, C., \& Thomas, J. (2012). Finding relevant studies. In D. Gough, S. Oliver, \& J. Thomas (Eds.), An introduction to systematic reviews (pp. 107-134). London: Sage.

Cockbain, E., \& Bowers, K. (2015). The faces and places of trafficking for labour exploitation: A large-scale analysis. Porto: Paper presented at the European Society of Criminology.

Cockbain, E., Bowers, K., \& Clark, J. (2014). Labour trafficking in Europe and its relationship with public health, safety and society. PROSPERO International Prospective Register of Systematic Reviews.

Degirmencioglu, S. M., Acar, H., \& Acar, Y. B. (2008). Extreme forms of child labour in Turkey. Children \& Society, 22(3), 191-200.

de Jonge, B. (2005). Eurojust \& Human Trafficking: The State of Affairs. Retrieved The Hague: Eurojust

Dettmeijer-Vermeulen, C., Boot-Matthijssen, M., van Dijk, E., de Jonge van Ellemeet, H., Koster, D., \& Smit, M. (2006). Trafficking in Human Beings. Fifth report of the Dutch National Rapporteur. The Hague: BNRM.

Di Nicola, A. (2007). Researching into human trafficking: Issues and problems. In M. Lee (Ed.), Human trafficking (pp. 49-72). Cullompton: Willan.

Dutch National Rapporteur. (2009). Trafficking in Human Beings: Seventh Report of the Dutch National Rapporteur. The Hague: BNRM.

Eck, J., \& Spelman, W. (1987). Problem-Solving: Problem-Oriented Policing in Newport News. Retrieved from Washington, D.C.: Police Executive Research Forum

EPPI-Centre. (2010). EPPI-Centre Methods for Conducting Systematic Reviews (published 2007, updated 2010). London: EPPI-Centre.

Equality and Human Rights Commission. (2011). Inquiry into Human Trafficking in Scotland: Report of the Equality and Human Rights Commission. Publication location not provided: Equality and Human Rights Commission.

Esson, J. (2015). Better off at home? Rethinking responses to trafficked West African footballers in Europe. Journal of Ethnic and Migration Studies, 41(3), 512-530.

European Commission. (2012). The EU Strategy towards the Eradication of Trafficking in Human Beings 2012-2016. Brussels: European Commission.

European Commission. (2016). Report on the progress made in the fight against trafficking in human beings (2016) as required under Article 20 of Directive 2011/36/EU on preventing and combating trafficking in human beings and protecting its victims. Brussels: European Commission.

Eurostat. (2013). Trafficking in human beings (2013th ed.). Luxembourg: Eurostat.

Eurostat. (2015). Trafficking in human beings (2015th ed.). Luxembourg: Eurostat.

Farquet, R., Mattila, H., \& Laczko, F. (2005). Human Trafficking: Bibliography by Region. International Migration, 43(1/2), 301-342.

Feingold, D. (2010). Trafficking in Numbers: The Social Construction of Human Trafficking Data. In P. Andreas \& K. Greenhill (Eds.), Sex, Drugs and Body Counts: The Politics of Numbers in Global Crime and Conflict (pp. 46-74). New York: Cornell University Press.

Gavra, D., \& Tudor, D. (2015). Addressing the Problem: Institutional Factors that Facilitate Human Trafficking and Potential Preventative Measures through Communication. Paper presented at the Redefining Community in Intercultural Context (RCIC) 2015, Brasov.

Gjermeni, E., Van Hook, M. P., Gjipali, S., Xhillari, L., Lungu, F., \& Hazizi, A. (2008). Trafficking of children in Albania: patterns of recruitment and reintegration. Child Abuse \& Neglect, 32, 941-948.

Goodey, J. (2008). Human trafficking Sketchy data and policy responses. Criminology and Criminal Justice, $8(4), 421-442$ 
Gough, D. (2007). Weight of evidence: a framework for the appraisal of the quality and relevance of evidence. Research papers in education, 22(2), 213-228.

Gough, D., \& Thomas, J. (2012). Commonality and diversity in reviews. In D. Gough, S. Oliver, \& J. Thomas (Eds.), An introduction to systematic reviews (pp. 35-65). London: Sage.

Gough, D., Oliver, S., \& Thomas, J. (Eds.). (2012). An introduction to systematic reviews. London: Sage.

Government of the Netherlands. (2016). Team Work! Manual for experts on multidisciplinary cooperation against trafficking in human beings for labour exploitation. The Hague: Government of the Netherlands.

Goździak, E. M. (2008). On challenges, dilemmas, and opportunities in studying trafficked children. Anthropological Quarterly, 81(4), 903-924.

Gozdziak, E., \& Bump, M. (2008). Data and Research on Human Trafficking: Bibliography of ResearchBased Literature. Washington, D.C.: Georgetown University.

Gozdziak, E., Graveline, S., Skippings, W., \& Song, M. (2015). Bibliography of Research-Based LIterature on Human Trafficking: 2008-2014. Washington, D.C.: Georgetown University.

Home Office. (2007). Trafficking for the purposes of labour exploitation: A literature review. London: Home Office.

Home Office. (2011a). Future Directions in Organised Crime Research. London: Home Office.

Home Office. (2011b). Local to Global: Reducing the Risk from Organised Crime. London: Home Office.

Home Office. (2012). First annual report of the Inter-departmental Ministerial Group on Human Trafficking. London: Home Office.

Home Office. (2014). Modern Slavery Strategy. London: Home Office.

International Centre for Migration Policy Development. (2007). Listening to Victims: Experiences of identfication, return and assistance in South-Eastern Europe. Vienna: International Centre for Migration Policy Development.

International Centre for Migration Policy Development. (2010a). Study on Post-Trafficking Experiences in the Czech Republic, Hungary, Italy and Portugal. Vienna: International Centre for Migration Policy Development.

International Centre for Migration Policy Development. (2010b). Trafficking in Human Beings in Croatia: An Assessment Focusing on Labour Exploitation. Vienna: International Centre for Migration Policy Development.

International Labour Office. (2009). The cost of coercion: Global report under the follow-up to the ILO Declaration on Fundamental Principles and Rights at Work. Geneva: International Labour Office.

International Labour Organization. (1930). Forced Labour Convention (Convention C029). Geneva: International Labour Organization.

International Organization for Migration. (2010). The Causes and Consequences of Re-trafficking: Evidence from the IOM Human Trafficking Database. Geneva: International Organization for Migration.

Johnson, S. D., Tilley, N., \& Bowers, K. J. (2015). Introducing EMMIE: an evidence rating scale to encourage mixed-method crime prevention synthesis reviews. Journal of Experimental Criminology, 11(3), 459473.

Jokinen, A., \& Ollus, N. (2011). Trafficking for forced labour: Project Summary and Conclusions. In A. Jokinen, N. Ollus, \& K. Aromaa (Eds.), Trafficking for forced labour and labour exploitation in Finland, Poland and Estonia (pp. 312-323). Helsinki: HEUNI.

Jokinen, A., \& Ollus, N. (2013). Recruitment, Exploitation of Migrant Workers and Labour Trafficking in Finland, Sweden, Estonia and Lithuania: Introduction and Research Findings. In N. Ollus, A. Jokinen, \& M. Joutsen (Eds.), Exploitation of migrant workers in Finland, Sweden, Estonia and Lithuania: uncovering the links between recruitment, irregular employment practices and labour trafficking (pp. 9-30). Helsinki: HEUNI.

Kelly, L. (2002). Journeys of Jeopardy: A Review of Research on Trafficking in Women and Children in Europe. Geneva: International Organization for Migration.

Kelly, L. (2005). "You can find anything you want": A critical reflection on research on trafficking in persons within and into Europe. International Migration, 43(1-2), 235-265.

Laczko, F. (2005). Data and research on human trafficking. International Migration, 43(1-2), 5-16.

Laczko, F., \& Gozdziak, E. (2005). Data and Research on Human Trafficking: A Global Survey. Geneva: International Organization for Migration.

Laczko, F., \& Thompson, D. (Eds.). (2000). Migrant Trafficking and Human Smuggling in Europe: A review of the evidence with case studies from Hungary, Poland and Ukraine. Geneva: International Organization for Migration.

Lehti, M., \& Aromaa, K. (2006). Trafficking for sexual exploitation. Crime and justice, 34(1), $133-227$. https://doi.org/10.1086/650306. 
Lewis, H., Dwyer, P., Hodkinson, S., \& Waite, L. (2014). Precarious lives: Forced labour, exploitation and asylum. Bristol: Policy Press.

Liberati, A., Altman, D. G., Tetzlaff, J., Mulrow, C., Gøtzsche, P. C., Ioannidis, J. P., Clarke, M., Devereaux, P., Kleijnen, J., \& Moher, D. (2009). The PRISMA statement for reporting systematic reviews and metaanalyses of studies that evaluate health care interventions: explanation and elaboration. PLoS medicine, 6(7), e1000100.

Macy, R. J., \& Graham, L. M. (2012). Identifying domestic and international sex-trafficking victims during human service provision. Trauma, Violence, \& Abuse, 13(2), 59-76.

McHugh, M. L. (2012). Interrater reliability: the kappa statistic. Biochemia medica, 22(3), 276-282.

Migrant Rights Centre Ireland. (2007). No Way Forward, No Going Back: Identifying the Problem of Trafficking for Forced Labour in Ireland. Dublin: Migrant Rights Centre Ireland.

National Crime Agency. (2014). NCA Strategic Assessment: The Nature and Scale of Human Trafficking in 2013. London: National Crime Agency.

National Crime Agency. (2015). National Referral Mechanism Statistics - End of Year Summary 2014. London: National Crime Agency.

National Criminal Police. (2007). Trafficking in human beings for sexual and other purposes. Situation report 9. 1 January - 31 December 2006. Stockholm: National Criminal Police.

National Police Board. (2009). Trafficking in human beings for sexual and other purposes. Situation report 10. Stockholm: National Police Board.

National Police Board. (2010). Trafficking in human beings for sexual and other purposes. Situation report 11. Stockholm: National Police Board.

National Police Board. (2011). Trafficking in human beings for sexual and other purposes. Situation report 12. Stockholm: National Police Board.

National Police Board. (2012). Trafficking in human beings for sexual and other purposes. Situation report 13. Stockholm: National Police Board.

Oliver, S., \& Sutcliffe, K. (2012). Describing and analysing studies. In D. Gough, S. Oliver, \& J. Thomas (Eds.), An introduction to systematic reviews (pp. 135-152). London: Sage.

Oram, S., Stöckl, H., Busza, J., Howard, L. M., \& Zimmerman, C. (2012a). Prevalence and risk of violence and the physical, mental, and sexual health problems associated with human trafficking: systematic review. PLoS Med, 9(5), e1001224.

Oram, S., Ostrovschi, N. V., Gorceag, V. I., Hotineanu, M. A., Gorceag, L., Trigub, C., \& Abas, M. (2012b). Physical health symptoms reported by trafficked women receiving post-trafficking support in Moldova: prevalence, severity and associated factors. BMC Women's Health, 12(1), 1-9.

Organization for Security and Co-operation in Europe. (2008). Human trafficking for labour exploitation, forced and bonded labour: Identification, prevention, prosecution. Vienna: Organization for Security and Co-operation in Europe.

Organization for Security and Co-operation in Europe. (2014). Ending exploitation, ensuring that businesses do not contribute to trafficking of human beings. Duties of states and the private sector. Vienna: Organization for Security and Co-operation in Europe.

Ottisova, L., Hemmings, S., Howard, L. M., Zimmerman, C., \& Oram, S. (2016). Prevalence and risk of violence and the mental, physical and sexual health problems associated with human trafficking: an updated systematic review. Epidemiology and psychiatric sciences.

Oude Breuil, B. C. (2008). 'Precious Children in a Heartless World'? The Complexities of Child Trafficking in Marseille. Children \& Society, 22(3), 223-234.

Pearce, J. J., Hynes, H. P., \& Bovarnick, S. (2009). Breaking the Wall of Silence: Practitioners' Responses to Trafficked Children and Young People. London: NSPCC.

Rees, R., \& Oliver, S. (2012). Stakeholder perspectives and participation in reviews. In D. Gough, S. Oliver, \& J. Thomas (Eds.), An introduction to systematic reviews (pp. 17-34). London: Sage.

Rijken, C. (2011). Challenges and Pitfalls in Combating Trafficking in Human Beings for Labour Exploitation. In C. Rijken (Ed.), Combatting trafficking in human beings for labour exploitation (pp. 393-424). Nijmegen: Wolf Legal Publishers.

Ryazantsev, S. V., Karabulatova, I. S., Yureevna, S. S., Evgenyevna, P. E., \& Vladimirovich, M. R. (2015). Modern Aspects of Human Trafficking in the Context of Labor Exploitation and Irregular Labor Migration in the Russian Federation. Mediterranean Journal of Social Sciences, 6(3 S2), 67.

Serious Organised Crime Agency. (2011). NRM Statistical Data April 2009 to June 2011. London: Serious Organised Crime Agency.

Shamseer, L., Moher, D., Clarke, M., Ghersi, D., Liberati, A., Petticrew, M., Shekelle, P., \& Stewart, L. A. (2015). Preferred reporting items for systematic review and meta-analysis protocols (PRISMA-P) 2015: elaboration and explanation. Bmj, 349, g7647. 
Skrivankova, K. (2006). Trafficking for Forced Labour UK Country Report. London: Anti-Slavery International.

Surtees, R. (2007). Labour trafficking in South Eastern Europe: developing prevention and assistance programmes. Vienna: Nexus Institute to Combat Human Trafficking.

Surtees, R. (2008). Trafficking of men-a trend less considered: the case of Ukraine and Belarus. International Organization for Migration, Migration Research Series (36).

Surtees, R. (2014). At sea: The trafficking of seafarers and fishers from Ukraine. In M. Dragiewicz (Ed.), Global human trafficking: critical issues and contexts (pp. 57-75). Abingdon: Routledge.

Tamas, A., Moise, A., Predut, C., \& Medvichi, N. (2013). Trafficking in Persons for Begging-Romania Study. Schweizerische Eidgenossenschaft and ANITP: Publication location not stated.

The Anti-Trafficking Monitoring Group. (2010). Wrong kind of victim? One year on: an analysis of UK measures to protect trafficked persons. London: Anti-Slavery International.

The Anti-Trafficking Monitoring Group. (2012). All change: Preventing trafficking in the UK. Retrieved from London. London: Anti-Slavery International.

Thomas, J., \& Harden, A. (2008). Methods for the thematic synthesis of qualitative research in systematic reviews. BMC medical research methodology, 8(45), 1-10.

Turner-Moss, E., Zimmerman, C., Howard, L. M., \& Oram, S. (2014). Labour Exploitation and Health: A Case Series of Men and Women Seeking Post-Trafficking Services. Journal of Immigrant and Minority Health, 16(3), 473-480.

Tyldum, G. (2010). Limitations in research on human trafficking. International Migration, 48(5), 1-13.

Tyldum, G., \& Brunovskis, A. (2005). Describing the unobserved: Methodological challenges in empirical studies on human trafficking. International Migration, 43(1-2), 17-34.

U.S. Department of State. (2001). Trafficking in Persons Report July 2001. RWashington, D.C.: U.S. Department of State.

U.S. Department of State. (2002). Trafficking in Persons Report June 2002. Washington, D.C.: U.S. Department of State.

U.S. Department of State. (2003). Trafficking in Persons Report June 2003. Washington, D.C.: U.S. Department of State.

U.S. Department of State. (2013). Trafficking in Persons Report June 2013. Washington, D.C.: U.S. Department of State.

U.S. Department of State. (2014). Trafficking in Persons Report June 2014. Washington, D.C.: U.S. Department of State.

UNICEF and Save the Children Norway. (2002). Research on Child Trafficking in Bosnia and Herzegovina. No publication location provided: UNICEF and Save the Children Norway.

United Nations. (2000). Protocol to prevent, suppress and punish trafficking in persons especially women and children. Vienna: United Nations.

United Nations Office on Drugs and Crime. (2012). Global Report on Trafficking in Persons 2012. Vienna: United Nations Office on Drugs and Crime.

United Nations Office on Drugs and Crime. (2014). Global Report on Trafficking in Persons 2014. Vienna: United Nations Office on Drugs and Crime.

Van Der Laan, P., Smit, M., Busschers, I., \& Aarten, P. (2011). Cross-border trafficking in human beings: Prevention and intervention strategies for reducing sexual exploitation: A Systematic Review. Campbell Systematic Reviews, 7(9).

Zielinski, C. (1995). New equities of information in an electronic age. BMJ, 310(6993), 1480-1481.

Zimmerman, C., Hossain, M., Yun, K., Roche, B., Morison, L., \& Watts, C. (2006). Stolen smiles: a summary report on the physical and psychological health consequences of women and adolescents trafficked in Europe. London: London School of Hygiene and Tropical Medicine.

Ella Cockbain is a lecturer at the Department of Security and Crime Science at University College London (UCL). She also holds a 'Future Research Leaders' Fellowship from the Economic and Social Research Council of the UK. Her research focuses on serious and organised crime and its prevention, especially human trafficking, forced labour and child sexual exploitation. She is the author of the book Offender and Victim Networks in Human Trafficking (Routledge, 2018).

Kate Bowers is a Professor of Security and Crime at the Department of Security and Crime Science at University College London (UCL). Her main research interests are in the use of quantitative techniques to examine and alleviate crime problems, focusing in particular on spatial and temporal crime patterns and evaluation methods. 
Galina Dimitrova holds an MSc in Countering Organised Crime and Terrorism from University College London (UCL), a B.A in Criminology from Edinburgh Napier University and an MSc in Accounting and Audit in the Public Sector from the Academy of Economics 'D.A. Tsenov - Svishtov' (Bulgaria). Her main area of research interest is the prevention and disruption of organised crime, in particular human trafficking. 